\title{
Development of a core outcome set for amblyopia, strabismus and ocular motility disorders: a review to identify outcome measures
}

Samia Al Jabri ${ }^{1}$, Jamie Kirkham² and Fiona J. Rowe ${ }^{1 *}$ (D

\begin{abstract}
Background: Core Outcome Sets (COS) are defined as the minimum sets of outcomes that should be measured and reported in all randomised controlled trials to facilitate combination and comparability of research. The aim of this review is to produce an item bank of previously reported outcome measures from published studies in amblyopia, strabismus and ocular motility disorders to initiate the development of COS.

Methods: A review was conducted to identify articles reporting outcome measures for amblyopia, strabismus and ocular motility disorders. Using systematic methods according to the COMET handbook we searched key electronic bibliographic databases from 1st January 2011 to 27th September 2016 using MESH terms and alternatives indicating the different subtypes of amblyopia, strabismus and ocular motility disorders in relation to treatment outcomes and all synonyms. We included Cochrane reviews, other systematic reviews, controlled trials, nonsystematic reviews and retrospective studies. Data was extracted to tabulate demographics of included studies, primary and secondary outcomes, methods of measurement and their time points.

Results: A total of 142 studies were included; 42 in amblyopia, 33 in strabismus, and 68 in ocular motility disorders (one study overlap between amblyopia and strabismus). We identified ten main outcome measure domains for amblyopia, 14 for strabismus, and ten common "visual or motility" outcome measure domains for ocular motility disorders. Within the domains, we found variable nomenclature being used and diversity in methods and timings of measurements.

Conclusion: This review highlights discrepancies in outcome measure reporting within published literature for amblyopia, strabismus and ocular motility and it generated an item bank of the most commonly used and reported outcome measures for each of the three conditions from recent literature to start the process of COS development. Consensus among all stakeholders including patients and professionals is recommended to establish a useful COS.
\end{abstract}

Keywords: Amblyopia, Strabismus, Ocular motility disorders, Outcome measures, Core outcome set

\footnotetext{
*Correspondence: rowef@liverpool.ac.uk

'Department of Health Services Research, University of Liverpool, Waterhouse

Building Block B, 2nd Floor, 1-3 Brownlow Street, L69 3GL Liverpool, UK

Full list of author information is available at the end of the article
}

(c) The Author(s). 2019, corrected publication March/2019. Open Access This article is distributed under the terms of the Creative Commons Attribution 4.0 International License (http://creativecommons.org/licenses/by/4.0/), which permits

unrestricted use, distribution, and reproduction in any medium, provided you give appropriate credit to the original author(s) and the source, provide a link to the Creative Commons license, and indicate if changes were made. The Creative Commons Public Domain Dedication waiver (http://creativecommons.org/publicdomain/zero/1.0/) applies to the data made available in this article, unless otherwise stated. 


\section{Background}

Amblyopia, strabismus and ocular motility disorders occur in about $10 \%$ of the general population (amblyopia $2-5 \%$, strabismus 4\%) [1]. They often present as childhood conditions and can constitute long-term problems for children and young adults. Strabismus and ocular motility disorders can also develop as acquired conditions due to neurological, endocrine and traumatic causes. There are several approaches to the management of these conditions including occlusion, penalisation, spectacles, prisms, drugs, surgery, botulinum toxin, exercises, watchful waiting, or a combination of two or more of the above [2]. The effects from these treatments such as improvements in symptoms or side effects are assessed by outcome measures and are usually used to formally evaluate management options in clinical studies. However varied outcome measures and several endpoints are often used [3-5]. This lack of standardisation makes it difficult to compare the conclusions of these studies and, as a result, renders it challenging to discuss realistically the likely outcomes of treatment with patients in the clinic [6].

One strategy suggested to overcome the issues resulting from variable outcome measures is the development of Core Outcome Sets (COS). This is defined as the minimum set of outcomes that should be measured and reported in all randomised controlled trials [7]. The COS will make it easier for the results of trials to be compared, contrasted and combined, lead to research that is more likely to have measured relevant outcomes due to involvement of relevant stakeholders, and enhance the value of evidence synthesis by ensuring that all trials contribute usable information [7]. Therefore, it is postulated that the use of COS would increase the potential in carrying out future meta-analysis for target conditions.

The numerous and diverse outcome measures that may be used for amblyopia, strabismus and ocular motility disorders include, amongst others, visual acuity, angle of deviation, range of ocular movements, fixation stability and binocular vision measurements. There are a number of Cochrane systematic reviews that consider a range of treatment trials for amblyopia, strabismus and ocular motility disorders. Their recommendations call for clarification of dose/response effect and further investigation of treatment regimens [2-4]. An attempt to utilise a COS is evident for the National Strabismus Data Set project [8]. A recent review recommended four outcomes for reporting results of surgery for intermittent exotropia [5] but was limited by the extent of literature review and lack of external consensus. A short narrative review of outcome measurements for size of deviation showed considerable variability across the tests available and the recommendations for their use [9].
Development of a COS involves a number of stages that commence with a systematic review of the literature to identify existing knowledge about outcome measures [7]. This is then followed by qualitative studies, Delphi surveys to consult widely on outcome measures and finally, consensus meetings to discuss and agree on the COS [7]. This paper reports the first stage - the literature review to identify the reported range of outcome measures in the published literature for amblyopia, strabismus and ocular motility disorders.

\section{Objectives}

The primary aim of this review is to generate an item bank of relevant outcome measures previously reported by researchers and clinicians in studies of treatment of conditions under evaluation. The review aims also to determine the variation in measuring methods used and timings of assessments.

The secondary objectives of this review are to investigate sources of variability of outcome measure definitions including different age groups, study designs, types of amblyopia (e.g. refractive, strabismic, stimulus deprivation), types of strabismus (e.g. exotropia, esotropia), and types of ocular motility disorder (e.g. accommodation and convergence disorders, mechanical restrictions, myogenic, neurogenic, nystagmus, patterns deviation and gaze palsy).

\section{Methods}

A protocol for the development of this COS project was written by a steering committee - a team of stakeholders including COS developers, ophthalmologists, orthoptists and journal editors. The review protocol was registered in the COMET initiative website (http://www.comet-initiative.org/studies/details/900?result=true) and published as open access (http://pcwww.liv.ac.uk/ rowef/index_files/Page356.htm). The review, using systematic rigorous methods, was conducted in accordance with the guidelines from the COMET handbook [7]. A PRISMA checklist [10] has been completed for the systematic review and can be found in Additional file 1 : Table S1.

\section{Eligibility criteria \\ Age}

Subjects of all ages with target conditions were included. Target conditions:

1. Amblyopia (unilateral, bilateral) of any type or severity (refractive, meridional, ametropic, strabismic or stimulus deprivation).

2. Strabismus (latent, manifest, constant, intermittent, micro) of any type and severity (eso, exo, hyper, hypo, cyclo deviation) 
3. Ocular motility disorders (OMDs) of any type and severity (nystagmus, horizontal/vertical gaze palsy, cranial nerve palsy, convergence/divergence disorder, patterns of horizontal incomitance, mechanical restrictions, myogenic disorders like thyroid eye disease and myasthenia with ocular involvement).

We included all three target conditions in recognition of the considerable overlap between them, for example amblyopia and strabismus often coexist with presentation in childhood with frequent persistence to adult life; whilst strabismus and ocular motility disorders often coexist with onset at any age through childhood and adult life.

\section{Interventions}

We included any intervention that aimed to improve the conditions of amblyopia, strabismus and ocular motility disorders or alleviate their associated visual symptoms. Interventions may include prisms, occlusion, optical penalisation, glasses, exercises, behavioural vision training, extraocular muscle surgery, extraocular muscle injection of botulinum toxin, pharmacology therapy, and watchful waiting/observation.

\section{Comparisons}

We included any comparison between the effectiveness of a treatment modality with another or with no treatment for each condition.

\section{Outcome measures}

We included any reported outcome measure that was recorded using any possible instrument or method at any point of time from the intervention.

\section{Types of studies}

The following types of studies were considered to be included in this review:

- Cochrane systematic reviews

- Systematic reviews (with or without meta-analysis) inclusive of diagnostic test accuracy reviews

- Randomised controlled trials (RCT)

- Controlled clinical trials (CCT)

- Cohort studies

- Case series with $>10$ subjects

We excluded all case reports and letters/editorials.

\section{Search methods for identification of studies}

We used systematic strategies to search key electronic databases. We searched Cochrane registers and electronic bibliographic databases including CENTRAL, ovid MEDLINE, SCOPUS, CINAHL, AMED and PsycINFO with search dates of 1st January 2011 through to 27th of
September 2016. This period was selected given the considerable increase in studies, trials and reviews in recent years and to extract treatment outcome measures that are relevant to recent research and clinical practice. As per COMET handbook guidance [7] we recognised that overly large reviews would be resource intensive and might not yield important additional outcomes.

We did not search for unpublished studies or in clinical trials registries and we did not hand-search any additional resources. We performed citation tracking using Web of Science Cited Reference Search for all included studies and searched the reference lists of included trials and review articles. Studies identified from the combined search were exported to an EndNoteX7 library. Search terms included a comprehensive range of $\mathrm{MeSH}$ terms and alternatives.

SJ and senior author FR developed the table of search terms jointly to include all target conditions and all synonyms of outcome measures, outcomes or assessments. Appropriate Boolean operators were obtained using University of Liverpool library online resources. Whenever available, the filters of "limit to humans" and "exclude case reports" were applied to the search in the databases. An example for search terms for one database is outlined in Additional file 2: Table S2. There was no language restriction while carrying out the search. The search strategy was discussed with and approved by the study steering committee.

\section{Selection of studies}

During the first stage of selection, SJ screened the titles and abstracts identified from the search that had been exported to an EndNoteX7 database. Senior researchers (FR and JJK) were consulted when there was a doubt about any abstract. Full text papers were accessed for all papers whose title and/or abstract met the eligibility criteria. These full text papers of potentially relevant studies were considered in the second stage of selection in which the selection criteria were again applied to the full paper content. We resolved disagreements by discussion.

The study protocol was registered in the COMET initiative website. We planned to include systematic reviews, controlled trials, non-systematic reviews, prospective and retrospective cohort studies as well as case series with $>10$ subjects at the time of writing the protocol for this systematic review. However this was not done in the actual review (protocol deviation) due to the excessive number of studies that met the inclusion criteria from the higher quality papers of systematic reviews and RCTs/CCTs for most conditions (Fig. 1).

Only a sample of non-systematic reviews and cohort studies was used (as the next best evidence quality to $\mathrm{RCTs} / \mathrm{SRs}$ ) to supplement this review when the number of studies from RCT/SRs for a particular sub-condition 


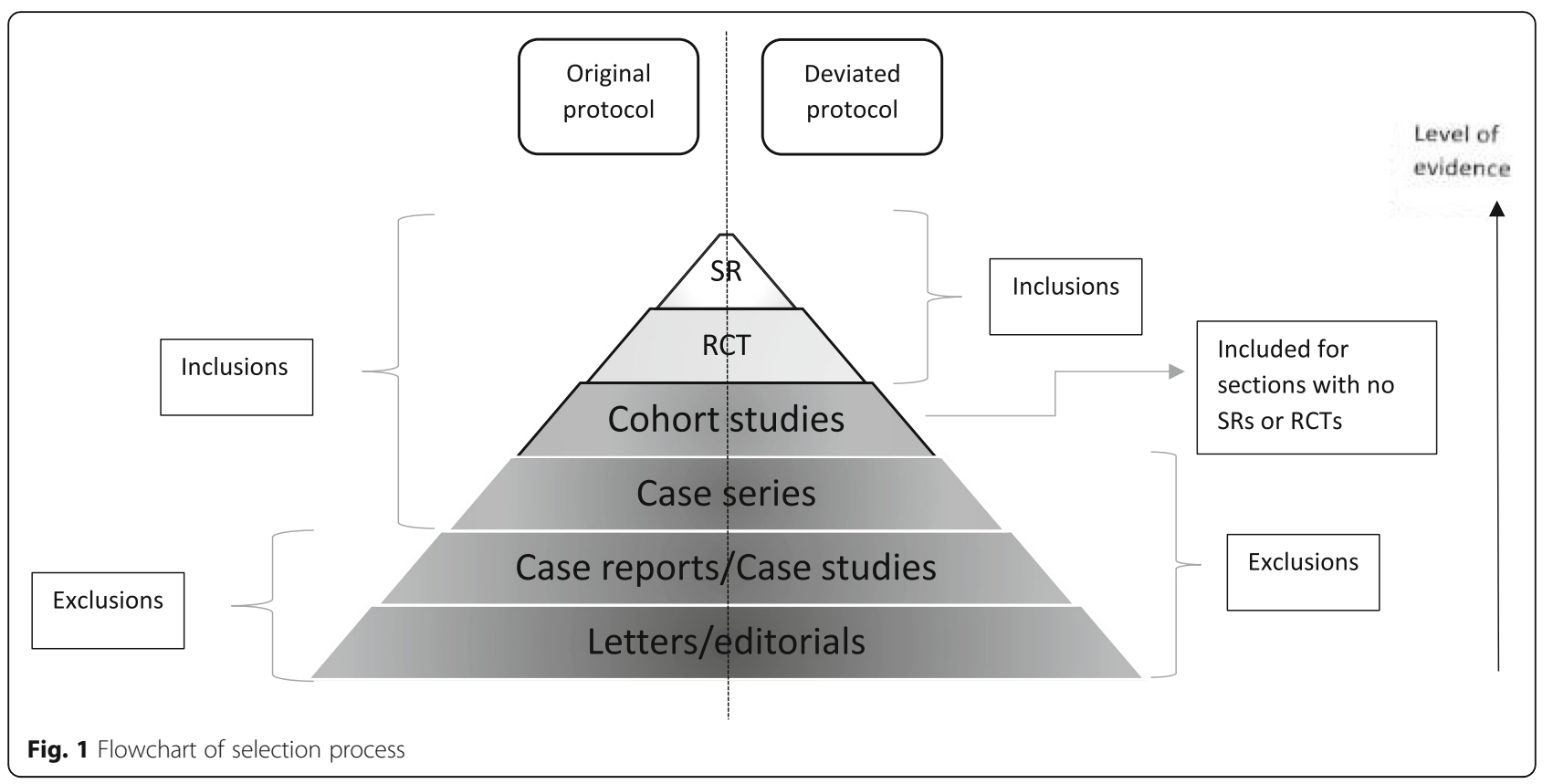

was sparse. We performed this also to check for any potentially important missed outcome measures from RCTs/SRs, e.g. long-term outcome measures or adverse events. The sample was variable depending on the availability of articles within the search results pertaining to a certain condition. The sample was increased until outcome measure saturation was achieved, defined as when no additional new measures could be identified and they were repetitive across studies. One non-systematic review and four retrospective studies for the ocular motility disorder sub-condition "pattern deviation" were included as we could not identify any relevant RCTs/SRs from the search results.

\section{Data extraction}

SJ extracted the data using a pre-determined data extraction form. Senior reviewer FR reviewed 20\% of studies to confirm fulfilling data extraction. There were no disagreements or inconsistencies.

The following data was extracted from each study:

Demographics

1. Study type.

2. Author details.

3. Year and journal of publication.

4. Country where study was conducted.

5. Condition(s) under investigation (amblyopia/ strabismus/ocular motility disorder).

6. Age of participants in the study population.

Outcome measures

1. The designated outcome measure (primary and secondary).
2. Outcome measurements (methods or instruments of measurements).

3. The time points at which they were measured.

\section{Data analysis and presentation}

All data was extracted verbatim from the source manuscripts to facilitate external critical review of the COS right back to its inception. Different nomenclature or aspects used to indicate the same outcome measure were grouped within main outcome headings (domains) when applicable to facilitate easy classification of outcome measures. For example for amblyopia the following aspects were recorded under the outcome measure heading of visual acuity (VA): best corrected visual acuity (BCVA), near visual acuity and binocular visual acuity. They were all recorded as reported in individual studies and then grouped together under one main outcome measure (VA). The method of measurement for BCVA was reported; e.g. using "Electronic Early Treatment Diabetic Retinopathy Study (ETDRS) VA protocol" or "Snellen chart" etc. and in addition we recorded the time when the measurement was made.

A similar classification and tabulation of information regarding the different outcome measures for the different conditions and sub-conditions was used. For the purpose of this study we did not perform a quality assessment for outcome data from the included studies as we sought only to create an item bank of all utilised outcome measures and outcome measurements. Hence a critique of the methodological quality of the studies was not necessary [7]. 
We generated an item bank of relevant outcome measures for amblyopia, strabismus and ocular motility disorders presented in percentages of frequency in included studies. In addition we produced an inventory of methods of measurements and their timings. Ocular motility disorders outcome measures were further stratified by sub-condition.

\section{Results}

\section{Study selection}

Electronic search of the six databases returned 22,217 hits, which were exported to the reference manager "EndNote X7". Titles were screened and the number reduced after removing duplicates and non-relevant papers to 2982 reports (Fig. 2). Another 1260 papers were excluded after screening the abstracts.

We were left with 1722 potentially relevant reports to our review question and meeting our eligibility criteria in review protocol (systematic reviews, controlled trials, cohort studies, and case series with $>10$ patients for target conditions and populations). Due to the large number of the potently eligible papers, we considered a modification to our eligibility criteria stated previously in the study protocol. We consulted the COMET handbook in which it is suggested, as an option, to perform the systematic review in stages to check if outcome saturation is reached [7] We took a decision, as a first stage analysis (protocol deviation, Fig. 1), to include only systematic reviews and controlled trials initially. This presented us with a total of 165 studies. Out of those, 53 studies were excluded after reading full articles due to irrelevance or lack of "visual or ocular motility" outcomes leaving us with 112 eligible systematic reviews and trials.

Then, when no systematic reviews or trials were found to cover a particular sub condition, cohort studies were considered as the next stage of the analysis. Moreover, we included additional non-systematic reviews distributed across the different conditions and sub conditions

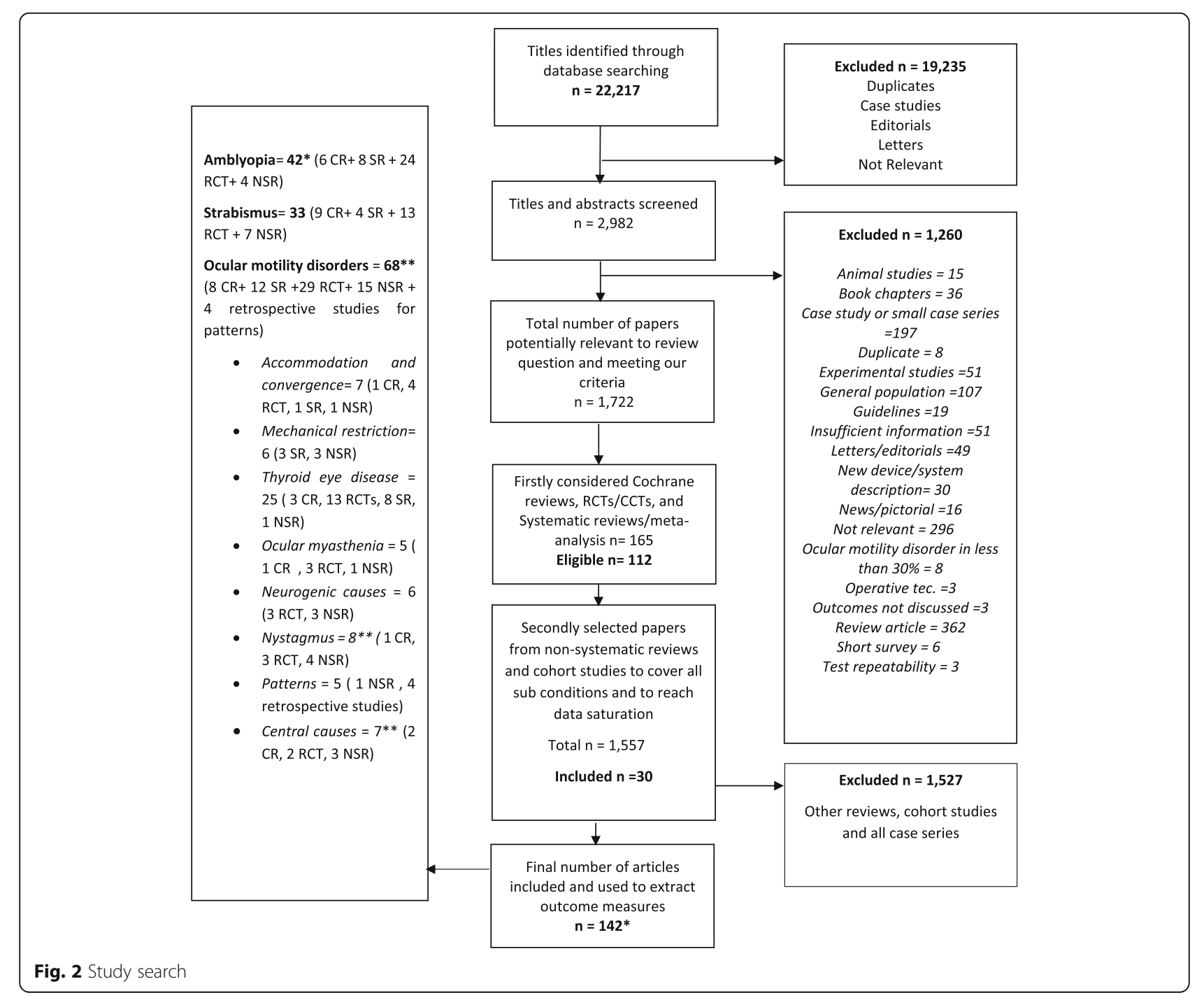


of motility disorders to ensure a comprehensive literature review and data saturation. The included number of both cohort studies and non-systematic reviews was 30 in total (4 cohort and 26 non-systematic reviews).

The total number of studies included in analysis in this review eventually was 142 unique studies. The studies came from a wide range of countries with predominance from the United States, the United Kingdom, China and various European countries (Fig. 3).

The following sections will present our findings individually for each of the three conditions: Amblyopia, Strabismus and OMDs outlining types of included studies, types of the conditions, age groups and treatments and listing outcome measures, measurements and commenting on timings. Further subgroup analysis is carried out for OMDs sub-conditions.

\section{Amblyopia}

\section{Types of included studies}

In this review we looked at a total of 42 studies in amblyopia including six Cochrane reviews, eight systematic reviews and meta-analysis, 24 controlled trials and four non-systematic reviews.

\section{Types of amblyopia and included age groups}

The types of amblyopia targeted in included studies ranged from childhood amblyopia [1, 11-42] to residual amblyopia in older children [43, 44], adolescents or adults [40, 41, 45, 46], unilateral [3, 12] and bilateral [3], refractive [3], anisometropic [19, 23], strabismic [24, 47], and stimulus deprivation amblyopia [48].

\section{Types of treatment}

Interventions varied from the "gold standard" refractive correction and occlusion or atropine penalization [24, 27, $30,31]$ to the more modern controversial treatments such as low-level laser [46], photic stimulation [43], and medical and behavioural treatment [45] which were more likely to be used beyond the visual maturation age when conventional treatments often fail.

Occlusion dosages and approaches were investigated in a number of included studies such as part-time versus full time occlusion [38], personalized versus standardized [33], and occlusion versus Bangerter filters [23]. Atropine penalization versus patching, and atropine combined with plano lenses were investigated in three of the included studies [20,31,34].

Binocular training with interactive computerized games or video clips versus monocular occlusion treatment were under investigation in seven studies [12, 22, 25, 28, 35, 36, 40]. Levodopa was the main treatment used in two studies $[16,44]$ and Citocolin combined with patching was used to treat residual amblyopia in older children in one of the included studies [29]. Acupuncture and Chinese medicine were the main therapeutic intervention for amblyopia in six of the included [11, 18, 19, 21, 32, 49].

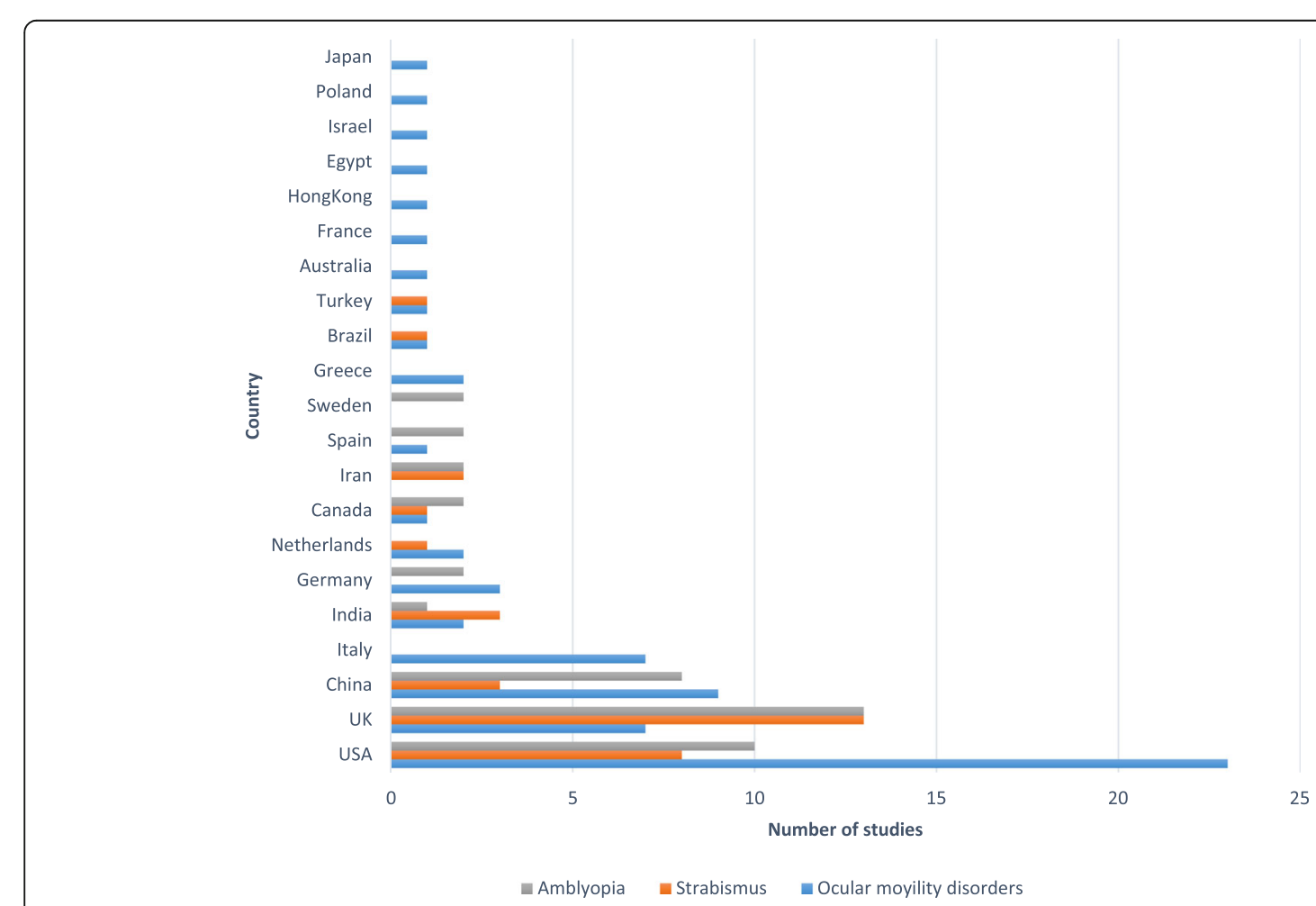

Fig. 3 Distribution of included studies by countries where they were conducted 


\section{Outcome measure domains}

We identified ten domains of outcome measures in these studies (Table 1): "visual acuity" (86\%), "stereopsis or sensory outcomes" (40\%), "adverse events" (33\%), "health-related quality of life" (HRQoL) (21\%), "compliance" (19\%), "refractive outcomes" (12\%), "ocular alignment" (10\%), "economic data" (7\%), "visual evoked potential" (VEP) (5\%), and "detection by photoscreeners" (2\%).

\section{Outcome measure subdomains and measurements}

Visual acuity The majority of studies (86\%) measured visual acuity (VA) as the primary outcome measure.
Variable descriptions used included improvement in VA $[11,18,25,28,32,35,39,45,47]$, mean VA [3, 12, 13, $23,40,44,48]$, median change in VA [23, 24], and "an increase of two or more lines of visual acuity or a final visual acuity of 20/25 or better" [20]. We identified a minority of subdomains of the outcome VA being reported by single studies such as near VA to compare it to distance visual acuity prior to amblyopia treatment [17] and "binocular VA" [39].

The LogMAR unit was universally used by all studies to report VA $(n=38)$ however different charts and distances were used depending on varying factors such as participant's age or setting. Relative to studies that

Table 1 Amblyopia outcome measures and measurements

\begin{tabular}{|c|c|c|c|c|}
\hline $\begin{array}{l}\text { Outcome measure } \\
\text { domain }\end{array}$ & $\begin{array}{l}\text { Studies reported the outcome } \\
\text { measure }(n / 42)\end{array}$ & $\begin{array}{l}\text { Variable subdomains of outcome } \\
\text { measure }\end{array}$ & Variable outcome measurements & References \\
\hline Visual acuity & $36(86 \%)$ & $\begin{array}{l}\text { BCVA (median/ mean change,IOD, } \geq 2 \text { line } \\
\text { improvement) } 38 \\
\text { Uncorrected Distance Visual Acuity UDVA } \\
1 \\
\text { Near Visual Acuity } 1 \\
\text { Binocular VA } 1\end{array}$ & $\begin{array}{l}\text { Age appropriate test } 23 \\
\text { HOTV } 7 \\
\text { ETDRS } 5 \\
\text { Snellen eye chart } 4 \\
\text { The Crowded Acuity Test } \\
\text { (Glasgow Acuity Test) } 2 \\
\text { Tumbling E charts } 2 \\
\text { Bailey-Lovie } 1 \\
\text { Allen Figs. } 1\end{array}$ & {$[3,11-20,22-34,36-40,43-48]$} \\
\hline Stereopsis & $17(40 \%)$ & $\begin{array}{l}\text { Near Stereopsis/ } \\
\text { binocularity/sensory outcomes } 16 \\
\text { Stereo sensitivity } 1\end{array}$ & $\begin{array}{l}\text { Randot Preschool Stereoacuity } \\
\text { Test } 4 \\
\text { Lang stereo test II } 2 \\
\text { Bagolini glasses response (at near } \\
\text { \& distance) } 2 \\
\text { The Frisby test } 2\end{array}$ & $\begin{array}{l}{[11,12,15,20,23-28,31,34,36,} \\
39,42,45,48]\end{array}$ \\
\hline Adverse events & $14(33 \%)$ & & & $\begin{array}{l}{[3,11-13,15,16,25,27,34,35} \\
44,47-49]\end{array}$ \\
\hline $\begin{array}{l}\text { Health-related } \\
\text { quality of life }\end{array}$ & $9(21 \%)$ & $\begin{array}{l}\text { HRQoL } 9 \\
\text { Emotional impact } 1 \\
\text { Social stigma scores } 1\end{array}$ & $\begin{array}{l}\text { Amblyopia Treatment Index } 4 \\
\text { Amblyopia } \\
\text { and Strabismus Q } 2 \\
\text { Psychological Impact Q } 2 \\
\text { Patching Success Q } 1 \\
\text { CVFQ } 1 \\
\text { SPPC } 1 \\
\text { VF-14 } 1 \\
\text { Protection Motivation Theory Q } 1 \\
\text { Interviews } 1 \\
\text { Mean Rutter behaviour scores } 1\end{array}$ & {$[3,11,12,15,37,41,47,48,50]$} \\
\hline Compliance & $8(19 \%)$ & & $\begin{array}{l}\text { Objective occlusion dose } \\
\text { monitoring } 3 \\
\text { Parental treatment diaries } 2\end{array}$ & {$[12,15,25,27,30,34,37,44]$} \\
\hline Refractive outcomes & $5(12 \%)$ & $\begin{array}{l}\text { Median spherical equivalent } 3 \\
\text { Refractive outcome } 2 \\
\text { Spherical and cylindrical refraction } 1\end{array}$ & $\begin{array}{l}\text { Manifest and cycloplegic } \\
\text { refractions } 1\end{array}$ & {$[13,14,23,24,31]$} \\
\hline Ocular alignment & $5(12 \%)$ & & $\begin{array}{l}\text { Simultaneous prism and } \\
\text { Cover test SPCT } 4 \\
\text { Cover test } 1\end{array}$ & {$[27,31,34,42,44]$} \\
\hline Economic data & $3(7 \%)$ & $\begin{array}{l}\text { Cost data } 3 \\
\text { Cost- effectiveness } 1\end{array}$ & & {$[3,47,48]$} \\
\hline $\begin{array}{l}\text { Visual evoked } \\
\text { potentials }\end{array}$ & $2(5 \%)$ & $\begin{array}{l}\text { M-VEP amplitude \& latency } 1 \\
\text { VEP latency } 1\end{array}$ & & {$[16,46]$} \\
\hline $\begin{array}{l}\text { Detection by } \\
\text { Photoscreeners }\end{array}$ & $1(2 \%)$ & & $\begin{array}{l}\text { MTI photoscreener } 1 \\
\text { PowerRefractor } 1 \\
\text { PowerRefractor II } 1 \\
\text { Plusoptix photoscreener series } 1 \\
\text { iScreen } 1 \\
\text { Spot } 1\end{array}$ & [1] \\
\hline
\end{tabular}


specified which charts were used, the most commonly reported tests were "Isolated Crowded Amblyopia Treatment Study HOTV for subjects aged 3 to $<7$ years" [14, 17, 27, 34, 39, 44, 45] and "Electronic Early Treatment Diabetic Retinopathy Study VA protocol for subjects aged 7 or older" [14, 27, 34, 44, 45]. "Snellen chart" was reported as an alternative by a lesser number of studies $[14,16,39,45]$ and "Crowded Acuity Test" was used in two studies [30, 43].

Stereopsis/sensory outcomes These were reported in $17 / 42(40 \%)$ of the studies. In one study "stereo-sensitivity" was reported rather than stereopsis, in order to be able to represent nil stereoacuity by zero, which therefore can facilitate quantitative analysis as suggested by Tsirlin et al. [45].

Seven out of 17 of the studies did not report a particular outcome measurement, however the unit was given as "seconds of arc" in six studies [11, 12, 20, 23, 28, 42]. To measure near stereoacuity, "Randot Preschool test" was reported in four studies [27, 31, 34, 45], "Frisby test" in two $[26,45]$, and "Lang stereo test II" in two studies $[23,24]$. "Bagolini glasses at distance \& near" was used in addition, to determine lower levels of binocularity in the same previous two studies by Agervi et al. [23, 24].

Adverse events The reported variants of this outcome measure included "diplopia" [12, 35, 47, 48], "occlusion amblyopia" [12, 47], "visual disorientation" [47], "skin irritation" [15], and "allergy to patches" [47, 48]. Adverse events were assessed using "a survey containing 17 items with a Likert scale completed by child and parent" in the RCT of Levodopa in older children by the Pediatric Eye Disease Investigator Group (PEDIG) [44]. The remaining studies did not give a particular method to gather this outcome measure.

HRQoL This is increasingly being reported as an outcome measure in the treatment of amblyopia. The studies reported more than ten different instruments. The most commonly reported questionnaire in these was "The Amblyopia Treatment Index (ATI)" [37, 41, 50, $51]$.

Compliance This was assessed using "objective occlusion dose monitoring" in three studies [12, 30, 37], by discussions with the parent [34], or review of a calendar log maintained by the participant and parent [44].

Ocular alignment Interestingly ocular alignment was not reported as an outcome measure in the majority of the included studies (88\%), even for strabismic amblyopia. However, it was highlighted in the PEDIG trials where it was measured using a "simultaneous prism and cover test" [27, 31, 34, 44] and in one Cochrane review where it was measured using "cover test" [42].

Refractive outcomes "Median spherical equivalent" [14, $23,24]$ and "spherical and cylindrical refraction" [13] have been reported in included studies.

Visual evoked potential (VEP) VEP was reported as a secondary outcome in addition to visual acuity in the study conducted by Ivandic et al. after the use of low laser for adolescents and adults with amblyopia [46]. "Multifocal visual evoked potentials (M-VEP) amplitude and latency" was measured in a number of the subjects in the trial. Another example of using "VEP latency" as an outcome measure was reported by Yang et al. in a meta-analysis looking at studies that used Levodopa in the treatment of amblyopia in children $<18$ years of age [16].

\section{Timing of measurements}

We found variable timings that ranged from six weeks (post binocular training) [35, 40] to three years (post strabismus surgery in amblyopia [42], and post auricular point sticking therapy [18]. However 10 weeks [25, 27, 34], 6 months [11, 32, 40] and 12 months [3, 12, 29, 47, 48 ] were the commonest timings given. Long-term outcomes were measured at 15 years of age in the RCT of "Atropine vs patching for treatment of moderate amblyopia" by the PEDIG [31] and at seven years of age in the review of "Occlusion for stimulus deprivation amblyopia” [48].

\section{Strabismus}

\section{Types of included studies}

We included 33 strabismus studies distributed as nine Cochrane reviews, four systematic reviews,13 controlled trials, and seven non-systematic reviews.

\section{Types of strabismus and included age groups}

This review included outcome measures extracted from studies investigating a wide range of strabismus types in different age groups.

While strabismus in general was under evaluation in around one third of the included studies (33\%), intermittent exotropia by itself was the focus in more than one third (36\%). This might be a reflection of the fact that intermittent exotropia is a common form of childhood exotropia [52]. Moreover, it is well established that it is one of the commonest worldwide constituting around $25 \%$ of all strabismus types [5].

On the other hand, esotropia was the target condition in only five studies (15\%) with "Infantile esotropia" being the type in four of them [53-56] and "High AC/A ratio esotropia in teenagers" in one [57]. Three vertical strabismus studies were also among studies included in our 
review; two on dissociated vertical deviation (DVD) management $[58,59]$ and another on inferior oblique overaction [60].

The majority of subjects targeted in included strabismus studies were from the paediatric age group. In this review more than half of strabismus studies had children less than 18 years of age as participants compared to only $12 \%$ for adults [61-64]. The remaining studies were either generalised for adults and children $[2,4,5,58,60$, 65-68] or did not state a specific age group [52, 59, 69].

\section{Types of treatment}

Over half of the studies (52\%) discussed outcome measures following surgical interventions for strabismus, most commonly muscle surgery $(45 \%)[5,42,55,56,60$, $61,64-72]$ and less for botulinum toxin injection [2, 54]. Muscle surgery and botulinum toxin injection were both combined in one study [63]. In contrast, non-surgical or conservative treatments were evaluated in five of included studies (15\%) [52, 57, 73-75]. Another 15\% of studies involved both surgical and non-surgical interventions and reported treatment outcome measures following either method $[4,53,58,59,76]$.

\section{Outcome measure domains}

We identified 14 domains of outcome measures for strabismus (Table 2). The four most commonly reported ones were "motor alignment" (79\%), "binocularity" (64\%), "adverse events" (61\%), and "health-related quality of life" (48\%). The less commonly reported outcome measures included "visual acuity" (24\%), "control of deviation" (24\%), "fusional vergence" (15\%), "ocular movements" (9\%) and "AC/A ratio" (3\%).

\section{Outcome measure subdomains and measurements}

Motor alignment/angle of deviation This was reported as "motor alignment" or "angle of deviation" in 26/33 studies. This was further described to be measured "at near and distance" in seven studies out of these $[4,5,63$, $66,70,71,77]$.

In 12 studies alignment was measured using "prism alternate cover test PACT" $[4,5,54,58,59,63,67,70,71$, $74,77,78]$ and /or with "simultaneous prism cover test SPCT" in eight studies [4, 53, 63, 66, 74, 75, 77, 79]. "Cover test" was reported in five studies [2, 42, 73, 74, 79], "Synoptophore" in four $[2,4,42,53]$ and "Hirschberg test" in three [54, 73, 79]. Krimsky test was reported as an alternative test in subjects with poor cooperation in one study [54], when cover tests are not applicable [63] or in cases with poor vision (worse than 20/200) in one RCT [60].

It is noteworthy that there is still no total agreement on the definition of a successful ocular alignment [5], varying from 5 to 8 to $10 \mathrm{PD}$ from orthophoria. However there was a considerable agreement on defining success in included studies as orthophoria within $10 \mathrm{PD}$ $[2,42,53,61,65,74,80]$.

Stereopsis/sensory outcomes Sensory outcomes were either reported as any level of "binocularity/stereopsis" $[2,52,55,57-59,67]$, or as "stereoacuity" (near or presumably near) $[5,56,60,71,73,76,77,79]$, or both; with "binocularity" and "stereoacuity" stated as two distinct outcome measures [42]. Additionally, "steroacuity at near and distance" was measured in four of intermittent exotropia studies $[4,66,68,74]$.

The outcome measurement used to assess stereoacuity were similar to those found in amblyopia studies, "Randot stereoacuity test" [71, 73, 74], with the addition of Titmus Housefly [42, 55, 60] and TNO [52, 66, 67]. "Sensory fusion" was measured with "Worth's 4 dots" test in two studies [42, 67]. In one review, a stepwise approach of assessing binocularity was undertaken. After "stereoacuity" (the gold standard), "simultaneous perception" and "motor fusion" were considered next [53].

Adverse events These included postoperative alignment complications such as "induced A or V pattern" [60, 70], "induced vertical deviation" $[2,54]$ "development of DVD" [56, 60], "induced incomitance" [69, 71], or visual complications such as intolerable diplopia $[2,65]$ and "development of amblyopia" [4, 53].

Other adverse events specified in included studies were "globe perforation" [65, 70, 78], and "induced ptosis" post botulinum toxin injection [2, 53, 54].

Long-term change following surgical procedures including "recurrence of deviation" [68], "overcorrection" $[4,78]$ and "re-operation rate/number of operations needed" [53, 55, 65, 78] were reported.

HRQoL This was assessed using different questionnaires that could be generic (for example SF-36) [61, 62], or specific to age (for example EYE-Q) [77, 78], specific to vision (for example VFQ-25) [58] or specific to condition (for example the IXTQ) [5, 50, 51, 62, 72, 77].

Strabismus and amblyopia were often combined in the same HRQoL questionnaire (for example the A\&SQ) $[50,61,62,64]$.

Visual acuity Only $24 \%$ of included strabismus studies reported BCVA as an outcome measure. LogMAR or LogMAR equivalent was the most reported unit used $[42,52,63,79]$.

Control of deviation This outcome measure was reported in seven intermittent exotropia studies [5, 52, 68, 74, 76-78]. Different scores were used including 
Table 2 Strabismus outcome measures and measurements

\begin{tabular}{|c|c|c|c|c|}
\hline $\begin{array}{l}\text { Outcome measure } \\
\text { domain }\end{array}$ & $\begin{array}{l}\text { Studies reported the } \\
\text { outcome measure } \\
(\mathrm{n} / 33)\end{array}$ & $\begin{array}{l}\text { Variable subdomains of outcome } \\
\text { measure }\end{array}$ & Variable outcome measurements & References \\
\hline Motor alignment & $26(79 \%)$ & $\begin{array}{l}\text { Motor alignment / } \\
\text { angle of deviation } 26 \\
\text { Orthotropia or microtropia } 1 \\
\text { Manifest strabismus } 1 \\
\text { Hyperdeviation } 1\end{array}$ & $\begin{array}{l}\text { Prism and alternate cover test } 12 \\
\text { Simultaneous prism and cover test } 8 \\
\text { Cover-uncover test } 5 \\
\text { Synoptophore } 4 \\
\text { Alternate cover test } 3 \\
\text { Hirschberg test } 3 \\
\text { Krimsky } 3 \\
\text { Prism Bar Cover Test } 1 \\
\text { Prism under cover test } 1 \\
\text { Corneal reflection tests } 1\end{array}$ & $\begin{array}{l}{[2,4,5,42,52-60,63} \\
65-68,70,71,74-79]\end{array}$ \\
\hline Binocularity & $21(64 \%)$ & $\begin{array}{l}\text { Presence and quality of binocularity } \\
\text { /binocular single vision } 9 \\
\text { Stereoacuity at near } 8 \\
\text { Steroeacuity at near \& distance } 4 \\
\text { Sensory fusion } 2\end{array}$ & $\begin{array}{l}\text { Randot stereoacuity test } 3 \\
\text { TNO } 3 \\
\text { Titmus Housefly } 3 \\
\text { Bagolini glasses } 2 \\
\text { Worth's } 4 \text { dot test } 2 \\
\text { Frisbye Davis Distance (FD2) } \\
\text { stereotest } 1 \\
\text { Simultaneous perception } 1 \\
\text { Suppression } 1 \\
\text { Presence of monofixation } 1\end{array}$ & $\begin{array}{l}{[2,4,5,42,52,53,55-} \\
60,66-68,71,73,75- \\
77,79]\end{array}$ \\
\hline Adverse events & $20(61 \%)$ & $\begin{array}{l}\text { Induced A or V pattern } 2 \\
\text { Induced vertical deviation } 2 \\
\text { Development of DVD } 2 \\
\text { Induced incomitance } 2 \\
\text { Intolerable diplopia } 2 \\
\text { Development of amblyopia } 2 \\
\text { Induced ptosis } 2 \\
\text { Long-term Change: re-operation rate/ } \\
\text { recurrence /overcorrection/post-opera- } \\
\text { tive drift } 2 \\
\text { Subconjunctival haemorrhage } 1 \\
\text { Discomfort/abnormal } \\
\text { sensory experiences } 1\end{array}$ & Tangent screen (in degrees) 1 & $\begin{array}{l}{[2,4,5,42,53-56,58-} \\
61,63,65,68-71,76 \\
78]\end{array}$ \\
\hline $\begin{array}{l}\text { Health-related quality } \\
\text { of Life }\end{array}$ & $16(48 \%)$ & $\begin{array}{l}\text { Improvement in quality of life } 14 \\
\text { Patient satisfaction } 2 \\
\text { Anxiety } 1 \\
\text { Depression } 1 \\
\text { Social anxiety and social avoidance } 1 \\
\text { Well-being } 1\end{array}$ & $\begin{array}{l}\text { Intermittent Exotropia Q } 6 \\
\text { Amblyopia and Strabismus Q } 4 \\
\text { Adult Strabismus Q } 4 \\
\text { Age-specific QoL assessments } 2 \\
\text { SF-36/ SF-8/ SF-12 } 2 \\
\text { EQ-5D } 2 \\
\text { NEI-VFQ } 2 \\
\text { VF-14 } 2 \\
\text { EYE-Q } 2 \\
\text { Quality of life questionnaires } 2 \\
\text { Vision-specific quality-of-life instru- } \\
\text { ments } 1 \\
\text { Any measure of patient or parent } \\
\text { satisfaction relating to improvement } \\
\text { to lifestyle } 1 \\
\text { VFQ-25 } 1 \\
\text { The amblyopia treatment index } 1 \\
\text { CVFQ } 1 \\
\text { VQoL_CYP } 1 \\
\text { CAT-QOL } 1 \\
\text { PPQ } 1 \\
\text { LVP-FVQ } 1\end{array}$ & $\begin{array}{l}{[2,4,5,50,51,53,57} \\
58,61,62,64,65,72, \\
73,78,79]\end{array}$ \\
\hline Visual acuity & $8(24 \%)$ & $\begin{array}{l}\text { VA tests/BCVA } 5 \\
\text { Amblyopia } 3\end{array}$ & $\begin{array}{l}\text { Log MAR or log MAR equivalent } 4 \\
\text { Snellen } 1\end{array}$ & $\begin{array}{l}{[42,52,59,63,73,77-} \\
79]\end{array}$ \\
\hline Control of deviation & $8(24 \%)$ & $\begin{array}{l}\text { Control } 7 \\
\text { Control of the near angle } 1 \\
\text { Ability to maintain /control phoria } \\
\text { with a filter } 1 \\
\text { Control of DVD } 1\end{array}$ & $\begin{array}{l}\text { Newcastle } \\
\text { Control Score } 5 \\
\text { Holmes and Mohney Office Control } \\
\text { Scale } 2 \\
\text { Mayo Score } 2 \\
\text { Petrunak and Rao's five-point Scale } 1\end{array}$ & $\begin{array}{l}{[5,52,59,68,74,76,78,} \\
79]\end{array}$ \\
\hline
\end{tabular}


Table 2 Strabismus outcome measures and measurements (Continued)

\begin{tabular}{|c|c|c|c|c|}
\hline $\begin{array}{l}\text { Outcome measure } \\
\text { domain }\end{array}$ & $\begin{array}{l}\text { Studies reported the } \\
\text { outcome measure } \\
\text { (n/33) }\end{array}$ & $\begin{array}{l}\text { Variable subdomains of outcome } \\
\text { measure }\end{array}$ & Variable outcome measurements & References \\
\hline Fusional vergence & $5(15 \%)$ & $\begin{array}{l}\text { Fusional vergence or amplitude for } \\
\text { distance and near } 3 \\
\text { Motor fusion test at near or distance } \\
\text { or both } 2\end{array}$ & $\begin{array}{l}\text { Base out or base in prism test/ } \\
\text { Synoptophore } 1 \\
\text { A prism bar } 1\end{array}$ & {$[2,4,42,66,68]$} \\
\hline Economic outcomes & $4(12 \%)$ & $\begin{array}{l}\text { Economics (e.g. length of stay in } \\
\text { hospital, hours of surgeons time) } 2 \\
\text { Use of health-care resources } 2 \\
\text { NHS costs } 2 \\
\text { Costs to families accessing the } \\
\text { treatments } 2\end{array}$ & & {$[2,65,78,79]$} \\
\hline Ocular movements & $3(9 \%)$ & $\begin{array}{l}\text { Ocular movements } 3 \\
\text { Inferior oblique function } 1 \\
\text { DVD } 1 \\
\text { DHD } 1\end{array}$ & $\begin{array}{l}\text { Ordinal scale from } 0 \text { to } 4+\text {, grade } 0 \\
\text { or } 1+\text { is satisfactory } 1 \\
\text { DVD grading scale of } 1-41 \\
\text { DHD is measured by reversed } \\
\text { fixation test } 1\end{array}$ & {$[54,59,60]$} \\
\hline Re-operation rates & $2(6 \%)$ & & & {$[55,65]$} \\
\hline $\mathrm{AC} / \mathrm{A}$ ratio & $1(3 \%)$ & & & [52] \\
\hline $\begin{array}{l}\text { Abnormal head } \\
\text { posture }\end{array}$ & $1(3 \%)$ & & & [59] \\
\hline $\begin{array}{l}\text { Presence of latent } \\
\text { nystagmus }\end{array}$ & $1(3 \%)$ & & Video-oculography 1 & [59] \\
\hline $\begin{array}{l}\text { Detection of } \\
\text { strabismus using } \\
\text { refraction devices }\end{array}$ & $1(3 \%)$ & & Plusoptix Vision Screener 1 & [77] \\
\hline
\end{tabular}

TNO The Netherland Organisation, DVD Dissociated Vertical Deviation, DHD Dissociated Horizontal deviation, BCVA Best Corrected Visual Acuity, HR-QoL Healthrelated quality of life, Q questionnaire, SF Short Form, EQ5D EuroQoL-5D, EYE-Q Effects of Youngsters' Eyesight on Quality of Life, CVFQ Children's Visual Function Questionnaire, VQoL-CYP Vision-related Quality of Life of Children and Young People, CAT-QoL Children's Amblyopia Treatment Quality of Life Questionnaire, PPQ Perceived Psychosocial Questionnaire, LVP-FVQ LV Prasad-Functional Vision Questionnaire, NEI-VFQ National Eye Institute Visual Function Questionnaire, VF-14 Visual Function Index, NHS National Health Service

"Newcastle Control Score" [5, 52, 68, 77, 78], "Office Control Score" [5, 74], "Mayo Score" [77, 78] and "Petrunak and Rao's five point scale" [52]. "Control to show whether the deviation is latent or manifest" was also considered for DVD in the review by Christoff et al. [59].

Fusional vergence A further outcome was referred to as "fusional vergence for distance and near" in three [2, $66,68]$ or as "motor fusion at distance or near or both" in two studies $[4,42]$. It was measured in one included study using a "base out or base in prism test/synoptophore" [42] or "a prism bar" [66].

Ocular movements These were included in vertical strabismus such as DVD [59] and inferior oblique overaction [60]. Muscle action was documented on a grading scale from 1 to 4 [59] or 0-4 [60].

$\mathrm{AC} / \mathrm{a}$ ratio $\mathrm{AC} / \mathrm{A}$ ratio was reported as an outcome in a review by Piano et al. for the conservative treatment of intermittent distance exotropia [52].

\section{Timing of measurements}

The time of measurement varied between studies and did not clearly correlate with the intervention. The measurement was often done at multiple time points $[54,61,63,66,67,70,78]$ or at one time point otherwise. It ranged from one week [66] to three years [42, 73]. The most frequently given timings were 3 months $[54,60,61,63,66,69,70,72,78], 6$ months $[2,53,54$, $61,63,65-67,70,71,74-76,78]$ and one year $[58,61$, $63,64,67]$. Long-term outcomes were measured at age of six years in one study for infantile esotropia [55].

\section{Ocular motility disorders (OMDs) Types of included studies}

A total of 68 studies were included for ocular motility disorders (OMDs), distributed as eight Cochrane reviews, 12 systematic reviews, 29 controlled trials, 15 non-systematic reviews and four retrospective studies.

\section{Types of ocular motility disorders and included age groups}

We classified OMDs into seven sub-conditions. Table 3 gives an outline of the common outcome measures across these sub-conditions in included studies. 
Table 3 Ocular motility disorder sub-conditions and common outcome measures

\begin{tabular}{|c|c|c|c|c|c|c|c|c|c|c|}
\hline OMD sub- condition & $\begin{array}{l}\text { Range of eye } \\
\text { movement }\end{array}$ & HRQoL & Diplopia & VA & $\begin{array}{l}\text { Motor } \\
\text { alignment }\end{array}$ & $\begin{array}{l}\text { Adverse } \\
\text { events }\end{array}$ & AHP & $\begin{array}{l}\text { Patient } \\
\text { symptoms }\end{array}$ & BSV & Stereopsis \\
\hline $\begin{array}{l}\text { Accommodation \& convergence } \\
\text { disorders }\end{array}$ & & $\sqrt{ }$ & & $\sqrt{ }$ & $\sqrt{ }$ & & & $\sqrt{ }$ & & \\
\hline Mechanical \& paralytic & $\sqrt{ }$ & $\sqrt{ }$ & $\sqrt{ }$ & $\sqrt{ }$ & $\sqrt{ }$ & $\sqrt{ }$ & $\sqrt{ }$ & & & \\
\hline Myogenic & $\sqrt{ }$ & $\sqrt{ }$ & $\sqrt{ }$ & $\sqrt{ }$ & $\sqrt{ }$ & $\sqrt{ }$ & $\sqrt{ }$ & $\sqrt{ }$ & $\sqrt{ }$ & $\sqrt{ }$ \\
\hline Neurogenic & $\sqrt{ }$ & & $\sqrt{ }$ & $\sqrt{ }$ & $\sqrt{ }$ & $\sqrt{ }$ & $\sqrt{ }$ & & $\sqrt{ }$ & \\
\hline Nystagmus & $\sqrt{ }$ & $\sqrt{ }$ & & $\sqrt{ }$ & & $\sqrt{ }$ & $\sqrt{ }$ & & & \\
\hline Patterns & $\sqrt{ }$ & & & & $\sqrt{ }$ & $\sqrt{ }$ & & & & $\sqrt{ }$ \\
\hline Central causes & $\sqrt{ }$ & & $\sqrt{ }$ & & $\sqrt{ }$ & & $\sqrt{ }$ & $\sqrt{ }$ & $\sqrt{ }$ & $\sqrt{ }$ \\
\hline
\end{tabular}

$O M D$ ocular motility disorder, $H R Q O L$ Health-related quality of life, $V A$ visual acuity, $A H P$ abnormal head posture, $B S V$ binocular singe vision

Forty five per cent of included OMDs studies [81-116] had adults exclusively as subjects due to the nature of conditions under evaluation such as thyroid eye disease and neurological diseases with gaze palsies, which exist in adults typically. In contrast, less than tenth of the studies were done on paediatric subjects [117-124]. Some of these were for conditions found predominantly in teenagers such as convergence insufficiency and accommodation dysfunction and others included disorders with an early onset such as infantile nystagmus and pattern deviations. The remaining studies had mixed adults and children populations $(n=18 / 67)[80,125-141]$ or the age was not clear $(n=6 / 67)$ [142-147].

\section{Types of treatment}

Interventions used in these studies included medical, surgical and conservative measures.

\section{Outcome measure domains}

We identified ten domains of outcome measures common for the majority of OMDs (Table 4). The most frequently reported outcome measures were "range of eye movement" (34\%), "HRQoL" (28\%), "improvement in diplopia" (26\%), "visual acuity" (22\%) and "motor alignment" (21\%). Other less frequent outcome measures included "adverse events" (15\%), "improvement in symptoms" (13\%), "improvement in AHP" (10\%), "increasing field of BSV" (6\%) and "stereoacuity" (6\%).

\section{Outcome measure subdomains and measurements}

Range of eye movement This was the commonest outcome measure reported in general for OMDs and was included in all sub-conditions except for accommodation and convergence disorders. This was either included in composite scores or as a distinct outcome measure. In one RCT the nine positions of gaze were videotaped and measurements were done "directly on photographs drawing a horizontal straight line from internal canthus"
[102]. In another study this was described as "in 8 positions of gaze binocularly and monocularly" [132].

HRQoL HRQoL outcome measures were mostly prominent in thyroid eye disease studies [82, 84, 91, 95-97, $104,107,109-111,115,116]$, nevertheless they were also scattered in other sub-conditions; accommodation and convergence disorders [125], ocular myasthenia [142] and central causes of eye movement disorders [80, 81].

Improvement in diplopia This was another common outcome measure; however there was incongruity in the position of gaze free from diplopia. Position of gaze was mostly not indicated $[90,93,101,105,112,115,116$, $127,133,141,144,146]$, however improvement was confined to primary gaze in a number of studies $[106,108$, 114, 119].

Visual acuity Only $22 \%$ of the included studies reported visual acuity and these were mostly for nystagmus or orbital abnormalities. "Binocular visual acuity" was specifically additionally indicated in two of nystagmus studies $[85,126]$.

Motor alignment This was reported in all sub-conditions except nystagmus studies. Whenever reported, this was either assessed with cover/uncover/alternate cover test without quantification $[129,132]$ or quantified using "PACT" [138, 140] or "Krimsky" [138] in less cooperative patients. Moreover, in addition to horizontal and vertical deviation, torsion was evaluated in a number of pattern deviation studies objectively $[121,136,139,140]$ or less commonly subjectively [121].

\section{Timing of measurements}

Multiple time points [82, 92, 94, 96, 97, 100, 101, 103, $115,118,121,128]$ or spans of follow up were often given $[83,84,99,105,111,113,126,139]$. However 6 months $[82,83,97,99,103,104,111]$ and 12 months $[82,97,98,103,107,113]$ were frequent timings given in 
Table 4 Ocular motility disorder outcome measures and measurements

\begin{tabular}{|c|c|c|c|c|}
\hline $\begin{array}{l}\text { Outcome measure } \\
\text { domain }\end{array}$ & $\begin{array}{l}\text { Studies reported } \\
\text { the outcome } \\
\text { measure }(n / 68)\end{array}$ & $\begin{array}{l}\text { Variable subdomains of } \\
\text { outcome measure }\end{array}$ & $\begin{array}{l}\text { Variable outcome } \\
\text { measurements }\end{array}$ & References \\
\hline $\begin{array}{l}\text { Range of eye } \\
\text { movement }\end{array}$ & $23(34 \%)$ & $\begin{array}{l}\text { Range of eye movement/ } \\
\text { Change in extraocular } \\
\text { motility } 14 \\
\text { Determination of range of } \\
\text { motility } 4 \\
\text { Oculomotor range/ } \\
\text { amount of ductions } 4 \\
\text { Restriction of eye } \\
\text { movements } 3 \\
\text { Motility assessment } 3 \\
\text { Quantitative measurement } \\
\text { of eye movement } 1 \\
\text { Assessment of ocular } \\
\text { muscle contracture } 1\end{array}$ & $\begin{array}{l}\text { Gradation of movements } 2 \\
\text { A scale of }-4 \text { underaction to }+ \\
4 \text { overaction, with } 0 \text { being } \\
\text { normal } 2 \\
\text { Forced duction test } 2 \\
\text { The CROM score } 2 \\
A \text { and } V \text { patterns } 1 \\
\text { Two-step test } 1 \\
\text { Monocular (ductions) and } \\
\text { binocular (versions) } 1 \\
\text { Cover/uncover test } 1 \\
\text { Videotaped, measured the nine } \\
\text { positions of gaze directly on } \\
\text { photographs } 1 \\
\text { Downshoot } 1\end{array}$ & $\begin{array}{l}{[80-82,89,90,92,93,95,102,108,111,} \\
115,116,119,121,129,130,132,134 \\
138,139,141,144]\end{array}$ \\
\hline $\begin{array}{l}\text { Health-related quality } \\
\text { of Life }\end{array}$ & $19(28 \%)$ & $\begin{array}{l}\text { Improvement in HRQoL } 16 \\
\text { Patient satisfaction and } \\
\text { functional measurements } \\
2 \\
\text { Participant and physician- } \\
\text { reported global health } \\
\text { assessment } 1 \\
\text { Aesthetic outcome } 1 \\
\text { Appearance of the eye } 1 \\
\text { Functional outcome } 1 \\
\text { Being able to drive after } \\
\text { strabismus surgery } 1\end{array}$ & $\begin{array}{l}\text { Validated questionnaires } 6 \\
\text { Short Form } 36 \text { (SF-36) } 2 \\
\text { Sickness Index Profile (SIP) } 1 \\
\text { Visual analogue scale } 1 \\
\text { NEI-VFQ-25 } 3 \\
\text { Visual analogue scale } 1\end{array}$ & $\begin{array}{l}{[80,82,84,87,91,95-97,104,107,109-} \\
111,115,116,125,126,142,143]\end{array}$ \\
\hline $\begin{array}{l}\text { Improvement in } \\
\text { diplopia }\end{array}$ & $18(26 \%)$ & $\begin{array}{l}\text { Recovery in diplopia } 18 \\
\text { Disappearance of diplopia } \\
\text { in primary gaze } 2 \\
\text { No diplopia in primary } \\
\text { position and downgaze } \\
\text { with prisms or without } \\
\text { prisms } 1\end{array}$ & $\begin{array}{l}\text { Subjective diplopia score } \\
\text { (Gorman scale) } 5 \\
\text { Diplopia score within GO-QOL } \\
\text { questionnaire } 1 \\
\text { A field diplopia test } 1\end{array}$ & $\begin{array}{l}{[89,93,101,105,106,108,111,112,114-} \\
116,119,127,133,134,141,144,146]\end{array}$ \\
\hline Visual acuity & $15(22 \%)$ & $\begin{array}{l}\text { Visual Acuity/BCVA } 11 \\
\text { Binocular BCVA } 5 \\
\text { Near VA } 1 \\
\text { Estimated VA } 1\end{array}$ & $\begin{array}{l}\text { Log MAR or Snellen } 4 \\
\text { Snellen } 1 \\
\text { Pattern reversal VEP } 1 \\
\text { Subjective score within GO-QoL } \\
\text { questionnaire } 1\end{array}$ & $\begin{array}{l}{[85-87,96-98,101,108,112,119,120} \\
124,126,145,147]\end{array}$ \\
\hline Motor alignment & $14(21 \%)$ & $\begin{array}{l}\text { Deviation } 4 \\
\text { Objective torsion } 4 \\
\text { Ocular alignment } \\
\text { testing } 2 \\
\text { Phoria } 2 \\
\text { Alignment in primary } \\
\text { position } 1 \\
\text { Incomitance } 1 \\
\mathrm{~A} \& \mathrm{~V} \text { pattern } 1 \\
\text { Pattern deviation and } \\
\text { horizontal deviation } 2 \\
\text { Subjective torsion } 1\end{array}$ & $\begin{array}{l}\text { PACT } 2 \\
\text { Indirect ophthalmoscopy } 2 \\
\text { Cover tests } 1 \\
\text { PCT } 1 \\
\text { Krimsky } 1 \\
\text { Synoptophore } 1 \\
\text { Maddox rod to test } \\
\text { overcorrection }>20 \text { degrees } 1 \\
\text { Double Maddox rod test } 1\end{array}$ & $\begin{array}{l}{[106,110,121,124,128,130-132,134} \\
136,138-140,147]\end{array}$ \\
\hline Adverse events & $10(15 \%)$ & $\begin{array}{l}\text { Related to steroids } 2 \\
\text { Related to Rituximab } 1 \\
\text { Related to radiotherapy } 1 \\
\text { Related to acupuncture } 1 \\
\text { Surgical complications } 1 \\
\text { Vision loss/retro orbital } \\
\text { hematoma post } \\
\text { reconstruction } 1 \\
\text { Surgery-induced } \\
\text { strabismus or visual loss } 1 \\
\text { Post op drift } 1\end{array}$ & & $\begin{array}{l}{[82,84,93,99,111,126,127,130,136,} \\
146]\end{array}$ \\
\hline Improvement in & $9(13 \%)$ & $\mathrm{Cl}$ symptoms 5 & (CISS) Version-15/CISS score 6 & {$[80,117,123-125,127,128,137,147]$} \\
\hline
\end{tabular}


Table 4 Ocular motility disorder outcome measures and measurements (Continued)

\begin{tabular}{|c|c|c|c|c|}
\hline $\begin{array}{l}\text { Outcome measure } \\
\text { domain }\end{array}$ & $\begin{array}{l}\text { Studies reported } \\
\text { the outcome } \\
\text { measure }(n / 68)\end{array}$ & $\begin{array}{l}\text { Variable subdomains of } \\
\text { outcome measure }\end{array}$ & $\begin{array}{l}\text { Variable outcome } \\
\text { measurements }\end{array}$ & References \\
\hline symptoms & & $\begin{array}{l}\text { Ocular myasthenia } \\
\text { symptoms } 1 \\
\text { Oscillopsia or blur in } \\
\text { nystagmus } 1 \\
\text { Patient-reported } \\
\text { symptoms post brain } \\
\text { injury } 1\end{array}$ & $\begin{array}{l}\text { Patient record or notes/ } \\
\text { questionnaire } 1\end{array}$ & \\
\hline $\begin{array}{l}\text { Improvement in } \\
\text { abnormal head } \\
\text { posture }\end{array}$ & $7(10 \%)$ & & $\begin{array}{l}\text { (In degrees) } 2 \\
\text { Inspection } 1\end{array}$ & {$[106,120,126,129,131,132,134]$} \\
\hline $\begin{array}{l}\text { Increasing the field } \\
\text { of binocular single } \\
\text { vision (BSV) }\end{array}$ & $4(6 \%)$ & & $\begin{array}{l}\text { Goldman } \\
\text { perimeter with the } \\
\text { score system of } \\
\text { Sullivan } 1 \\
\text { Worth four dot test } 1 \\
\text { CROM device } 1\end{array}$ & {$[80,110,130,134]$} \\
\hline Stereopsis & $4(6 \%)$ & $\begin{array}{l}\text { Presence of stereopsis } 2 \\
\text { Steroacuity } 2\end{array}$ & TNO stereo test 1 & {$[80,106,124,140]$} \\
\hline
\end{tabular}

HR-QoL Health-related quality of life, $Q$ questionnaire, CROM cervical range of motion, NEI-VFQ National Eye Institute Visual Function Questionnaire, SF Short Form, $B C V A$ Best Corrected Visual Acuity, VEP Visual Evoked Potential, GO-QoL Graves Ophthalmopathy Quality of Life, APCT Alternate Prism Cover Test, PCT Prism Cover Test, TED Thyroid Eye Disease, CISS Convergence Insufficiency Symptom Survey, TNO The Netherland Organisation

thyroid eye disease studies. Twelve weeks timing was common for accommodation and convergence disorders $[117,118,125,128]$.

More details on included studies for amblyopia, strabismus and ocular motility disorders arranged alongside identified outcome measures, outcome measurements and timings are given in Additional file 3: Table S31, Additional file 4: Table S3.2, Additional file 5:: Table S3.3 and Additional file 6: Tables S4.1-4.7).

\section{Outcome measures per sub-condition Accommodation and convergence disorders $(n=7)$ (Additional file 6: Table S4.1)}

For this group of disorders, the most prominent outcome measures were "patient symptoms" recorded with "Convergence Insufficiency Symptom Survey (CISS)" (86\%). "Near point of convergence NPC" and "positive fusional vergence" were less common. Alignment measurement was not expansively assessed in included studies apart from measuring "phoria" in two studies [128, 147] or ruling out manifest strabismus with "cover test at distance and near" for inclusion in one trial [124] . "Amplitude of accommodation" [118, 128, 147], and "accommodative facility" [118, 147] were also reported. "Dynamic retinoscopy" was reported by one study [147].

\section{Ocular mechanical restriction $(n=6)$ (Additional file 6: Table S4.2)}

The outcome measures "resolution of diplopia", "motility assessment" and "alignment" were mutual with other OMDs.
However, in certain circumstances such as in acute orbital floor fractures, the outcome measures "oculocardiac reflex" [119],"visual acuity" [119, 141] and "pupillary function" [119] were important.

"Assessment of fractures and entrapment of soft tissue" was evaluated with radiographic imaging such as helical CT [119].

"Forced duction test" was reported to check muscle restriction and entrapment in two included studies [119, 122]. Other assessments done in orbital fractures included "globe integrity" [119], "globe dystopia" [119, 122] and "infraorbital hyposthaesia" [105, 119, 141]. A further outcome measure related to appearance was "resolution of enophthalmos" [105, 141, 146].

\section{Ocular myogenic disorders $(n=30)$ (Additional file 6: Table S4.3)}

Thyroid eye disease Treatment response in thyroid eye disease is commonly evaluated using composite scores such as "VISA" [109] and "EUGOGO score" [91, 92, 103]. Modified versions of existing scales are often developed and used (for example "modified EUGOGO" [101], and "modified Werner grading scale" for orbital inflammation [96]). In addition, we found a high frequency of a number of widely recognised scoring systems such as "The clinical activity score (CAS)" to assess disease activity [82, 84, 90, 92, 95, 97-99, 101, 103, 104, $108,110-112,114-116]$ and "NO SPECS" to assess disease severity. [82, 84, 90, 103, 104, 111].

"Subjective diplopia" was frequently assessed using "the Gorman diplopia score" [90, 95, 116]. Ocular muscle 
motility assessment was mostly involved within composite scores but occasionally measured with dedicated scores (for e.g. The Total Motility score (TMS)) [116]. Additional outcome measures reported by studies for thyroid eye disease included "the need for post treatment corrective procedures" [83, 84, 91, 98, 111], and "orbital volume/orbital fat and muscle volume”. [95, 112].

Ocular myasthenia gravis and progressive external ophthalmoplegia In addition to the previously stated outcome measures shared with other eye motility disorders such as "improvement in diplopia" $[127,133]$ and "eye movement measurement" [102], there were outcome measures specific to myasthenia reported by included studies. These included "quantitative ocular myasthenia gravis score (OMG) score" [142] and "progression to generalised myasthenia gravis" [127, 133, 142]. Other associated ocular motility abnormalities reported included "inter-saccadic fatigue", "gaze-paretic nystagmus", "fatigue of accommodation" and "reduced velocity of pupillary constriction" [133]. Quality of life was evaluated using "the 15-item Myasthenia Gravis quality of life scale" in one study [142].

\section{Ocular motility disorders secondary to neurogenic disorders} $(n=6)$ (Supp. Table 4.4)

These refer to conditions such as third, fourth and sixth cranial nerve palsies. Clinical outcome measures included here in addition were "palpebral fissure size" [93, 144] and "pupil size" [144] for third nerve palsy. Bi et al. used "The cervical range motion (CROM) score" to quantify diplopia in a pilot RCT on acupuncture for the treatment of oculomotor paralysis [93].

In the review by Engel, in congenital fourth nerve palsy, alignment was checked with "a more sensitive 2-step test" [131]. "Facial asymmetry" was evaluated, and "superior oblique muscle atrophy/absent trochlear nerve" were examined with "high definition MRI" in the same study [131]. "Abnormal head position" was measured objectively using "a goniometer" in degrees [131]. An important adverse event sought after treatment here included "secondary Brown syndrome" [131].

In sixth nerve palsy, motility outcomes were included to reveal any "degree of incomitance" while measuring deviation, and to check for "medial rectus muscle contracture" using "forced duction test" [130]. "Scott's force generation test" or "electrooculography/electromyography" were used to assess "lateral rectus muscle function" [130].

\section{Nystagmus $(\boldsymbol{n}=8)$ (Additional file 6: Table S4.5)}

Outcome measures that were shared with most of the remaining OMDs were "visual acuity" (75\%) [85-87, $120,126,145]$, "improved head posture" (25\%) [120,
126], "patient satisfaction" (25\%) [87, 126] and "range of eye movement" (13\%) [132]. However, it is important to note that vision in patients with nystagmus was assessed more comprehensively with additional specifications in a few studies; "binocular visual acuity" was reported in two studies [85, 126], "gaze-dependant visual acuity GDVA" in one study [86], "near visual acuity" in one study [87] and "estimated visual acuity using pattern reversal VEP" in one study for infantile nystagmus [126].

"Eye movement recordings" was included in six nystagmus studies (75\%) [85-87, 126, 132, 145]. Examples of the methods used to record eye movement included "3-D video-oculography" [87] and "an infrared video pupil tracker" [86]. Different specific characteristics of nystagmus were gathered from eye movement recordings including "foveation/recognition time" [126, 137], "broadening the null point" [137, 145], and "nystagmus waveform" [126, 145]. The specific symptom of "oscillopsia" was assessed in two included studies [120, 137].

\section{Pattern deviation ( $n=5$ ) (Additional file 6: Table S4.6)}

A special feature with this group of conditions was the torsion deviation measurement reported in $80 \%(n=4 / 5)$ of studies [121, 136, 139, 140]. "Objective torsion" using "indirect ophthalmoscopy" was more commonly reported [121, 136, 139, 140] than "subjective torsion using double Maddox rod test" [121]. An example of a grading scale used was " -4 underaction to +4 overaction with 0 being normal” [121].

\section{Ocular motility disorders secondary to central causes $(n=7)$ (Additional file 6: Table S4.7)}

These include gaze palsies and some forms of acquired nystagmus. In addition to the common outcome measures with other sub-conditions, there were others highlighted in a number of included studies. These comprised particular attention to "saccades and pursuits". Measurements were done using "the optokinetic drum" or "video-oculogarphy" [132]. "Near point of convergence" was reported in one study [106].

\section{Discussion}

Systematic reviews investigating various specialities including ophthalmology [148-151] are increasingly being performed. What is evident from many systematic reviews is that the results from included trials and studies cannot be meta-analysed because of the variation in outcome measures used across the studies. The COMET initiative calls for development of COS in order to provide a minimum set of outcome measures which will facilitate future synthesis of results. To our knowledge this is the first review using systematic methods in accordance with the COMET handbook aiming to develop an 
item bank of outcome measures in the treatment of amblyopia, strabismus and ocular motility disorders.

We chose to combine these conditions in one report due to the great overlap between them and their frequent co-existence in subjects. Indeed some might consider strabismus as a subset of ocular motility disorders and vice versa. For example esotropia from sixth cranial nerve palsy was classified under motility disorders while others may classify it under strabismus. Additionally, strabismus can cause or result from amblyopia, and similarly with ocular motility disorders with childhood onset. Therefore it is meaningful to consider them all in one generalised report.

Although we did not cover every type, this review includes outcome measures extracted from studies investigating a wide range of amblyopia, strabismus and ocular motility disorders in different age groups undergoing nearly all possible methods of interventions.

\section{Amblyopia}

Although we attempted to include all types of amblyopia in this paper, we found that the majority of the studied variants were anisometropic, strabismic and combined anisometropic and strabismic amblyopia. Even though aetiologies were different, therapeutic interventions and outcome measures were comparable.

This review found that VA is the only outcome measure agreed by the great majority of included amblyopia studies. Stereopsis, adverse events and HRQoL were also relatively common however they were reported by less than half of the studies. VA and stereopsis measurement methods largely depended on the age of subjects who were mostly from the paediatric age group.

BCVA is measured typically in children from around the age of 3-4 years as well as in adults. It is the most commonly used outcome to assess visual acuity in our review and in perhaps in general for any eye condition. However, it is increasingly recognised that it does not truly reflect visual function needed in normal daily activities [151]. Additional assessments that can give more information about visual function include contrast sensitivity, near visual acuity, reading speed and visual field sensitivity [151].

It is not uncommon to find older children and adults with residual amblyopia, and as a result various non-conventional therapies attempted to treat it beyond the plasticity period. When that is done visual function can be assessed using conventional methods in addition to more objective and sensitive methods especially in the research environment. VEP is one outcome measure used to assess visual function post treatment in older children and adults. It is recommended to use VEP latency rather than amplitude due to its higher sensitivity [46].
Due to the strong association between amblyopia and strabismus, we made the assumption that ocular alignment would be a standard outcome measure in amblyopia studies, which was not the case once results had been gathered and analysed. Only $12 \%$ of the studies included this outcome measure.

Regarding health-related quality of life, it is notable that treatment side effects and compliance are occasionally evaluated and reported within HRQoL questionnaires, i.e. collecting all subjective or patient-reported outcomes in one type of a composite score. Therefore a number of amblyopia studies that reported HRQoL did not consider adverse events or compliance as independent outcome measures.

The timing of reported measurements was variable between studies however the most frequent time point found here was 12 months.

\section{Strabismus}

There is nearly a total agreement on the necessity to measure motor alignment at distance and near using prism alternate cover test (PACT) or simultaneous prism cover test (SPCT) in ideal situations; and Krimsky in poor cooperation or low vision [60]. The difference between PACT and SPCT is that the first measures the alignment by covering each eye alternatively whereas the second measures alignment before binocular vision is disrupted. Generally the total misalignment measured by PACT is the most often one reported [77].

The other outcome measures reported by more than half of strabismus studies were "binocularity (stereopsis/ BSV)" and "adverse events". "HRQoL" was reported by just under half of included studies.

Binocularity was mostly measured in included studies using near stereopsis. We found that distance stereopsis is not typically assessed with the exception of intermittent exotropia. A moderate correlation was found between near and distance stereoacuity in previous studies [66] and most clinicians prefer to measure near stereoacuity over distance stereoacuity because of better patient cooperation [5]. On the other hand, some authors suggest that distance stereoacuity is a better indicator for intermittent exotropia progression [66]. For example, in the RCT conducted by Saxena et al., distance stereoacuity showed continued improvement for up to three months post treatment compared to one week for near stereoacuity [66].

HRQoL is a complex concept with wide variation in how people perceive it individually and within one individual over time [62]. There is no agreed definition of QoL [51] however it can be considered a reflection of one's overall well-being and life experience, which is affected by different factors including physical, psychosocial and environmental elements [62]. McBain et al. 
found that adults with strabismus can have one of two types of QoL concerns; for example there may be functional concerns for those with diplopia and psychosocial concerns for those with strabismus but no diplopia [62]. It must be highlighted that the aim of measuring HRQoL outcome is to provide appropriate support depending on specific concerns or needs. It seems nevertheless that there is still no total consensus on one method of measurement of HRQoL in strabismus and amblyopia and that there is room for further development to reach agreement.

In comparison to the agreement on the above measures, there was dissimilarity in measuring other outcome measures such as "visual acuity" and "control of deviation" for patients with strabismus.

This review found only one third of strabismus studies considering "visual acuity" important to measure after treatment. This could be partially explained by the fact that it is relevant mostly in children to check the status of amblyopia and that vision is not a primary concern when there is prior amblyopia in adults undergoing for example surgical correction.

Furthermore, there are a number of outcome measures relevant only in specific variants of strabismus for example "control of deviation" and "AC/A ratio". Control of deviation is pertinent mostly in cases of intermittent exotropia and DVD. AC/A ratio is important mostly in high AC/A esotropia.

"AC/A ratio" is often measured for intermittent exotropia as well. It was shown previously by some authors that lower $\mathrm{AC} / \mathrm{A}$ ratios were attained post extensive orthoptic exercises for intermittent distance exotropia [52]. However, due to technical difficulties in measurements and potential inaccuracies if occlusion is not used while measuring it to differentiate between true and pseudo divergence excess, it is challenging to use it as a standard test to guide treatment [52].

Six months was the most commonly given timing to report outcome measures post strabismus treatment although there was great variation between studies.

\section{Ocular motility disorders}

Agreement on outcome measures for OMDs was the least compared to amblyopia and strabismus probably due to the wider variation in clinical features and therefore we provided outcome measures per sub-condition. However we found a degree of overlap in some outcome measures between the seven categories such as "range of eye movement", "HRQoL" and "improvement in diplopia".

Generally, it seems that having a satisfactory "range of eye movement" was the preferred outcome measure in eye motility disorders and that measurement in both ductions and versions is recommended to differentiate restrictive from paralytic eye conditions.
"HRQoL" assessment was shown to be especially relevant in disfiguring conditions such as thyroid eye disease. The reason behind that is the previously noted psychological factors which do not correlate well with objective clinical measures for unclear reasons [107]. There have been various versions of Graves's ophthalmopathy QoL questionnaires, but once more there is no consensus regarding their use [109]. A common feature in such questionnaires however is addressing both visual and appearance-related aspects of QoL [97, 107, 110]. Some authors considered in addition evaluating long-term quality of life in this group of patients for up to 11 years [107].

Furthermore, for OMDs complicated with "diplopia", a primary outcome measure frequently emphasised here was to assess improvement or resolution of diplopia. However, it would be useful, we suggest, to have an agreement whether any improvement in diplopia would be acceptable or improvement in diplopia in primary gaze, down gaze, with or without prisms would be required to define success. Also whether subjective reports are sufficient or they need to be combined with objective measurement of "field of binocular single vision". Similarly for measurement of deviation or reporting "alignment", an indication whether orthophoria in primary gaze or in more positions of gaze to be planned or achieved would be more helpful.

"Improvement in head posture" was found often closely related to improvement in diplopia and alignment, however this review has shown that it was not consistently addressed in relevant studies. Reporting head posture improvement in relation to the null position was similarly incongruous in nystagmus studies.

On the other hand, when diplopia was not the only concern in the ocular motility disorder as in accommodation and convergence disorders, "improvement in symptoms" would be reported. "The Convergence Insufficiency Symptom Survey" appeared to be widely accepted for this purpose [117, 123, 125, 128, 147].

Although assessment of "visual acuity" is typically standard in eye conditions, it was not reported in $75 \%$ of included OMDs studies. As noted above, its measurement was shown to be vital in nystagmus patients mostly. However, consensus is needed about what category of visual acuity to measure. Vision assessment was also relevant in thyroid eye disease and orbital fracture for optic nerve function assessment in relation to orbital changes.

Timing of reported outcome measures here was variable due to various factors indicated above.

\section{Study strengths and limitations}

The strength of this work is that the review followed a prescribed process for the creation of an item bank of outcome measures [7]. The resultant item bank is a 
comprehensive list that underpins the first stage of the process to develop Core Outcome Sets for amblyopia, strabismus and ocular motility disorders.

On the other hand, despite some overlap between target conditions, the varied review scope and inclusion of a wide range of conditions together could be considered a limitation preventing us from finding all the relevant reported outcome measures for every target condition and sub-condition. Although generalised and overlapping outcome measures for amblyopia, strabismus and ocular motility disorders were extracted here, specific and more refined categories of outcome measures might have been overlooked.

Another potential limitation is the exclusion of other studies of lower quality than systematic reviews and controlled trials, which might have resulted in missing valuable sources of reported outcome measures in literature. It would not be possible however to include all types of studies for a wide group of conditions as in our review. This might be feasible for conditions/sub-conditions when investigated individually.

\section{Future work and recommendations}

We next plan to conduct an iterative consensus process (Delphi surveys and group meetings) with key stakeholders including patients, clinicians and researchers as the second stage of developing these COSs. This stage will be to standardise what to measure, i.e. outcome measures. Subsequent work will be required to standardise how to measure them, i.e. outcome measurements and later, when to measure them, i.e. timing of measurements.

In terms of developing "Core Outcome Sets", we suggest the inclusion of both subjective and objective outcome measures; and both positive (i.e. improvement from baseline) and serious negative outcomes (i.e. adverse events). Furthermore, choosing feasible and easily available assessments is important. We also recommend that "long-term outcomes", especially for known chronic conditions, are considered.

\section{Conclusions}

We generated lists of the most reported outcome measures for amblyopia, strabismus and ocular motility disorders within included studies with indications to specific outcome measures in certain sub-conditions. We also identified the most reported outcome measurements and their timings from intervention to some extent.

This review also demonstrates significant variation in outcome measure reporting within published studies in the three conditions confirming the challenge in efficient comparison, combination and synthesis of data.
Various factors might be responsible for inconsistency between studies in reported outcome measures in conditions targeted in this review including age group, type of condition and often researcher or clinician preferences. While some of these factors are understandably fixed, researchers and clinicians preferences can probably be unified and standardised.

Although common outcome measures and measurements from the literature are highlighted in this review, this does not imply that they are necessarily the most appropriate outcome measures to be used as "core outcome measures" in trials or clinical practice. Consensus among all stakeholders including patients, clinicians, and researchers is required to establish COS. International agreement would be ideal to maximise usefulness of research overall.

\section{Additional files}

Additional file 1: Table S1. PRISMA checklist. This table contains the different sections in the review with the items and the page(s) where these can be found. (DOC $66 \mathrm{~kb}$ )

Additional file 2: Table S2. Search terms of SCOPUS database. Terms and Boolean operators used to perform the search for the review in one example database- SCOPUS. (DOCX $19 \mathrm{~kb}$ )

Additional file 3: Table S3.1. Amblyopia included studies. Included studies for amblyopia arranged by type of study, study ID, title, outcome measure domain, outcome measurement and time of measurement. (DOCX $30 \mathrm{~kb}$ )

Additional file 4: Table S3.2. Strabismus included studies. Included studies for strabismus arranged by type of study, study ID, title, outcome measure domain, outcome measurement and time of measurement. (DOCX $34 \mathrm{~kb}$ )

Additional file 5: Table S3.3. Ocular motility disorders included studies. Included studies for ocular motility disorders arranged by sub-condition, study ID, title, outcome measure domain, outcome measurement and time of measurement. (DOCX $50 \mathrm{~kb}$ )

Additional file 6: Tables S4.1-4.7. Outcome measures per subcondition of ocular motility disorder, Reported outcome measures arranged alongside OMD sub-conditions, number of studies reporting outcome measures, outcome measurements and references. (DOCX 194 kb)

\section{Abbreviations}

A\&SQ: Amblyopia and Strabismus Questionnaire; AC/A ratio: Accommodative convergence/Accommodation ratio; AHP: Abnormal Head Posture; BCVA: Best Corrected Visual Acuity; BSV: Binocular Singe Vision; CAS: Clinical Activity Score; CCT: Controlled clinical trials; CISS: Convergence Insufficiency Symptom Survey; COMET: Core Outcome Measures in Effectiveness Trials; COS: Core Outcome Set; CROM: Cervical Range Of Motion; CT: Computerised Tomography; DHD: Dissociated Horizontal Deviation; DVD: Dissociated Vertical Deviation; ETDRS: Electronic Early Treatment Diabetic Retinopathy Study; EUGOGO score: EUropean Group On Graves' Orbitopathy;

GDVA: Gaze-dependent Visual Acuity; GO-QoL: Graves Ophthalmopathy Quality of Life; HRQoL: Health-Related Quality of Life; IXTQ: Intermittent Exotropia Questionnaire; Log MAR: Logarithm of the Minimum Angle of Resolution; M-VEP: Multifocal Visual Evoked Potentials; NO SPECS: No Signs or symptoms, Only signs, Soft tissue involvement, Proptosis, Extraocular muscle involvement, Corneal involvement, Sight loss; OMDs: Ocular motility disorders; OMG: Ocular Myasthenia Gravis; PACT: Prism Alternate Cover Test; PD: Prism Dioptre; PEDIG: Pediatric Eye Disease Investigator Group; PROMS: Patient-reported outcome measures; RCT: Randomised Controlled Trials; SPCT: Simultaneous Prism Cover Test; TED: Thyroid Eye Disease; 
TES: Total Eye Score; TMS: Total Motility Score; TNO: The Netherland Organisation; UDVA: Uncorrected Distance VA; VISA: Vision, Inflammation, Strabismus/restriction, and Appearance/exposure

\section{Acknowledgements}

We acknowledge the Ophthalmology Department at Aintree University Hospital in Liverpool, United Kingdom for their support to SJ.

\section{Funding}

$\mathrm{SJ}$ is a student at University of Liverpool funded by Sultan Qaboos University/Oman.

\section{Availability of data and materials}

The datasets used and/or analysed during the current study are available from the corresponding author on reasonable request.

\section{Authors' contributions}

The conception and design of this work was by senior author FR. Data collection, analysis and interpretation and drafting of the article was done mainly by SJ. Critical revision of the article and final approval of the version to be published was done by senior authors FR and JJK. All authors have read and approved the final manuscript and agreed with its submission for publication.

\section{Competing interest}

The authors declare that they have no competing interests.

\section{Ethics approval and consent to participate}

Not applicable.

\section{Publisher's Note}

Springer Nature remains neutral with regard to jurisdictional claims in published maps and institutional affiliations.

\section{Author details}

'Department of Health Services Research, University of Liverpool, Waterhouse Building Block B, 2nd Floor, 1-3 Brownlow Street, L69 3GL Liverpool, UK.

${ }^{2}$ Department of Biostatistics, University of Liverpool, Liverpool, UK.

Received: 7 July 2018 Accepted: 29 January 2019

\section{Published online: 08 February 2019}

\section{References}

1. Sanchez I, Ortiz-Toquero S, Martin R, De Juan V. Advantages, limitations, and diagnostic accuracy of photoscreeners in early detection of amblyopia: a review. Clin Ophthalmol. 2016;10:1365-73.

2. Rowe FJ, Noonan CP: Botulinum toxin for the treatment of strabismus. In: Cochrane Database of Systematic Reviews. John Wiley \& Sons, Ltd; 2012.

3. Taylor K, Powell C, Hatt SR, Stewart C: Interventions for unilateral and bilateral refractive amblyopia. In: Cochrane Database of Systematic Reviews. John Wiley \& Sons, Ltd; 2012

4. Hatt SR, Gnanaraj L: Interventions for intermittent exotropia. In: Cochrane Database of Systematic Reviews. John Wiley \& Sons, Ltd; 2013.

5. Chiu AK, Din N, Ali N. Standardising reported outcomes of surgery for intermittent exotropia--a systematic literature review. Strabismus. 2014;22(1):32-6.

6. Boers M, Kirwan JR, Wells G, Beaton D, Gossec L, d'Agostino MA, Conaghan PG, Bingham CO, Brooks P, Landewe R et al.: Developing Core Outcome Measurement Sets for Clinical Trials: OMERACT Filter 2.0. In. Great Britain: Elsevier Science B.V., Amsterdam.; 2014: 745

7. Williamson PR, Altman DG, Bagley H, Barnes KL, Blazeby JM, Brookes ST, Clarke M, Gargon E, Gorst S, Harman N, et al. The COMET Handbook: version 1.0. Trials. 2017;18(3):280.

8. Taylor RH: Guidelines for the management of strabismus in childhood. In. Royal College of Ophthalmology; 2012.

9. Rowe FJ: Ocular alignment and motility: moving variables in clinical trials. In. Bruges, Belgium. : 34th European Strabismological Association.; 2011: pp. 111-114.

10. Moher D, Liberati A, Tetzlaff J, Altman DG. Preferred reporting items for systematic reviews and meta-analyses: the PRISMA statement. Int J Surg. 2010;8:336-41.
11. Liu M-I, Li L, Leung ping C, Wang Chi C, Liu M, Lan L, Ren Y-I, Liang F-R: acupuncture for amblyopia in children. In: Cochrane Database of Systematic Reviews. John Wiley \& Sons, Ltd; 2011.

12. Tailor V, Bossi M, Bunce C, Greenwood JA, Dahlmann-Noor A: Binocular versus standard occlusion or blurring treatment for unilateral amblyopia in children aged three to eight years. In: Cochrane Database of Systematic Reviews. John Wiley \& Sons, Ltd; 2015.

13. Alió JL, Wolter NV, Piñero DP, Amparo F, Sari ES, Cankaya C, Laria C. Pediatric refractive surgery and its role in the treatment of amblyopia: metaanalysis of the peer-reviewed literature. J Refract Surg. 2011;27(5):364-74.

14. Pediatric Eye Disease Investigator G, Holmes JM, Lazar EL, Melia BM, Astle WF, Dagi LR, Donahue SP, Frazier MG, Hertle RW, Repka MX, et al. Effect of age on response to amblyopia treatment in children. Arch Ophthalmol. 2011;129(11):1451-7.

15. West S, Williams C. Amblyopia. Clinical Evidence. 2011.

16. Yang XB, Luo DY, Liao M, Chen BJ, Liu LQ. Efficacy and tolerance of levodopa to treat amblyopia: a systematic review and meta-analysis. Eur J Ophthalmol. 2013;23(1):19-26.

17. Pediatric Eye Disease Investigator G, Christoff A, Repka MX, Kaminski BM, Holmes JM. Distance versus near visual acuity in amblyopia. J Aapos. 2011; 15(4):342-4.

18. Gong RL. Observation on therapeutic effect of child amblyopia treated with auricular point sticking therapy. Zhongguo Zhenjiu. 2011;31(12):1081-3.

19. Lam DSC, Zhao JH, Chen LJ, Wang YX, Zheng CR, Lin QE, Rao SK, Fan DSP, Zhang $M Z$, Leung $P C$, et al. Adjunctive effect of acupuncture to refractive correction on Anisometropic amblyopia one-year results of a randomized crossover trial. Ophthalmology. 2011;118(8):1501-11.

20. Medghalchi A, Dalili S. A randomized trial of atropine versus patching for treatment of moderate amblyopia. Iran Red Crescent Med J. 2011;13(8):7-9.

21. Wu L, Zhang GL, Yang YX. Clinical study on electrical plum-blossom needle for treatment of amblyopia in children. Zhongguo Zhong Xi Yi Jie He Za Zhi Zhongguo Zhongxiyi Jiehe Zazhi/Chinese Journal of Integrated Traditional \& Western Medicine/Zhongguo Zhong Xi Yi Jie He Xue Hui, Zhongguo Zhong Yi Yan Jiu Yuan Zhu Ban. 2011:31(3):342-5.

22. Bau V, Rose K, Pollack K, Spoerl E, Pillunat LE. Effectivity of an occlusionsupporting PC-based visual training programme by horizontal drifting sinus gratings in children with amblyopia. Klinische Monatsblatter fur Augenheilkunde. 2012;229(10):979-86.

23. Agervi $P$, Kugelberg U, Kugelberg M, Zetterström C. Two-year follow-up of a randomized trial of spectacles alone or combined with Bangerter filters for treating anisometropic amblyopia. Acta Ophthalmol. 2013;91(1):71-7.

24. Agervi $P$, Kugelberg U, Kugelberg M, Zetterstrom C. Two-year follow-up of a randomized trial of spectacles plus alternate-day patching to treat strabismic amblyopia. Acta Opthalmologica. 2013;91(7):678-84.

25. Foss AJ, Gregson RM, Mackeith D, Herbison N, Ash IM, Cobb SV, Eastgate RM, Hepburn T, Vivian A, Moore D, et al. Evaluation and development of a novel binocular treatment (I-BiTTM) system using video clips and interactive games to improve vision in children with amblyopia ('lazy eye'): study protocol for a randomised controlled trial. Trials [Electronic Resource]. 2013; $14: 145$

26. Stewart CE, Wallace MP, Stephens DA, Fielder AR, Moseley MJ. The effect of amblyopia treatment on stereoacuity. J AAPOS. 2013;17(2):166-73.

27. Pediatric Eye Disease Investigator G, Wallace DK, Lazar EL, Holmes JM, Repka MX, Cotter SA, Chen AM, Kraker RT, Beck RW, Clarke MP, et al. A randomized trial of increasing patching for amblyopia. Ophthalmology. 2013;120(11): 2270-7.

28. Jafari AR, Shafiee AA, Mirzajani A, Jamali P. CAM visual stimulation with conventional method of occlusion treatment in amblyopia: a randomized clinical trial. Tehran University Med J. 2014;72(1):7-14.

29. Pawar P, Mumbare S, Patil M, Ramakrishnan S. Effectiveness of the addition of citicoline to patching in the treatment of amblyopia around visual maturity: a randomized controlled trial. Indian J Ophthalmol. 2014;62(2):124-9.

30. Pradeep A, Proudlock FA, Awan M, Bush G, Collier J, Gottlob I. An educational intervention to improve adherence to high-dosage patching regimen for amblyopia: a randomised controlled trial. Erratum appears in $\mathrm{Br}$ J Ophthalmol. 2014;98(7):865-70

31. Pediatric Eye Disease Investigator G, Repka MX, Kraker RT, Holmes JM, Summers Al, Glaser SR, Barnhardt CN, Tien DR. Atropine vs patching for treatment of moderate amblyopia follow-up at 15 years of age of a randomized clinical trial. Jama Ophthalmology. 2014;132(7):799-805. 
32. Han ZH, Qiu M. Randomized controlled clinical trials for treatment of child amblyopia with Otopoint pellet-pressure combined with Chinese medical herbs. Chen Tzu Yen Chiu Acupuncture Res. 2015;40(3):247-50.

33. Moseley MJ, Wallace MP, Stephens DA, Fielder AR, Smith LC, Stewart CE, Cooperative RS. Personalized versus standardized dosing strategies for the treatment of childhood amblyopia: study protocol for a randomized controlled trial. Trials [Electronic Resource]. 2015;16:189.

34. Pediatric Eye Disease Investigator G, Wallace DK, Lazar EL, Repka MX, Holmes JM, Kraker RT, Hoover DL, Weise KK, Waters AL, Rice ML, et al. A randomized trial of adding a Plano lens to atropine for amblyopia. J Aapos. 2015;19(1):42-8.

35. Herbison N, Mackeith D, Vivian A, Purdy J, Fakis A, Ash IM, Cobb SV, Eastgate RM, Haworth SM, Gregson RM, et al. Randomised controlled trial of video clips and interactive games to improve vision in children with amblyopia using the I-BiT system. Br J Ophthalmol. 2016;1:1-6. https://doi. org/10.1136/bjophthalmol-2015-307798.

36. Tang W, Wang X, Tao L. A comparative study on visual acuity and stereopsis outcomes between perceptual learning based on cloud services and conventional therapy for amblyopia. Zhonghua Shiyan Yanke Zazhi/Chinese Journal of Experimental Ophthalmology. 2016;34(5):426-31.

37. Stewart CE, Moseley MJ, Fielder AR. Amblyopia therapy: an update. Strabismus. 2011;19(3):91-8.

38. Matta NS, Silbert DI. Part-time vs. full-time occlusion for amblyopia: evidence for part-time patching. Am Orthopt J. 2013;63:14-8.

39. DeSantis D. Amblyopia. Pediatr Clin N Am. 2014;61(3):505-18.

40. Mansouri B, Singh P, Globa A, Pearson P. Binocular training reduces amblyopic visual acuity impairment. Strabismus. 2014;22(1):1-6.

41. Carlton J, Kaltenthaler E. Amblyopia and quality of life: a systematic review. Eye. 2011;25(4):403-13

42. Korah S, Philip S, Jasper S, Antonio-Santos A, Braganza A: Strabismus surgery before versus after completion of amblyopia therapy in children. In: Cochrane Database of Systematic Reviews. John Wiley \& Sons, Ltd; 2014

43. Evans BJ, Yu CS, Massa E, Mathews JE. Randomised controlled trial of intermittent photic stimulation for treating amblyopia in older children and adults. Ophthalmic \& Physiological Optics. 2011;31(1):56-68.

44. Pediatric Eye Disease Investigator G, Repka MX, Kraker RT, Dean TW, Beck RW, Siatkowski RM, Holmes JM, Beauchamp CL, Golden RP, Miller AM, et al. A randomized trial of levodopa as treatment for residual amblyopia in older children. Ophthalmology. 2015;122(5):874-81.

45. Tsirlin I, Colpa L, Goltz HC, Wong AM. Behavioral training as new treatment for adult amblyopia: a meta-analysis and systematic review. Invest Ophthalmol Vis Sci. 2015;56(6):4061-75.

46. Ivandic BT, Ivandic T. Low-level laser therapy improves visual acuity in adolescent and adult patients with amblyopia. Photomed Laser Surg. 2012; 30(3):167-71.

47. Taylor K, Elliott S. Interventions for strabismic amblyopia. Cochrane Database Syst Rev. 2011;8:CD006461.

48. Antonio-Santos A, Vedula SS, Hatt SR, Powell C. Occlusion for stimulus deprivation amblyopia. Cochrane Database Syst Rev. 2014;2:CD005136

49. Yan XK, Zhu TT, Ma CB, Liu AG, Dong LL, Wang JY. A Meta-Analysis of Randomized Controlled Trials on Acupuncture for Amblyopia. EvidenceBased Complementary and Alternative Medicine. 2011;(8):CD006461. https:// doi.org/10.1002/14651858.CD006461.pub3.

50. Carlton J, Kaltenthaler E. Health-related quality of life measures (HRQOL) in patients with amblyopia and strabismus: a systematic review. $\mathrm{Br} J$ Ophthalmol. 2011;95(3):325-30.

51. Tadic V, Hogan A, Sobti N, Knowles RL, Rahi JS. Patient-reported outcome measures (PROMs) in paediatric ophthalmology: a systematic review. $\mathrm{Br} J$ Ophthalmol. 2013:97(11):1369-81.

52. Piano M, O'Connor AR. Conservative management of intermittent distance exotropia: a review. Am Orthopt J. 2011;61(1):103-16.

53. Elliott S, Shafiq A. Interventions for infantile esotropia. Cochrane Database Syst Rev. 2013;7:CD004917.

54. Chen J, Deng D, Zhong H, Lin X, Kang Y, Wu H, Yan J, Mai G. Botulinum toxin injections combined with or without sodium hyaluronate in the absence of electromyography for the treatment of infantile esotropia: a pilot study. Eye. 2013;27(3):382-6.

55. Simonsz HJ, Kolling $\mathrm{GH}$. Best age for surgery for infantile esotropia. Eur J Paediatr Neurol. 2011;15(3):205-8.

56. Hug D. Management of infantile esotropia. Curr Opin Ophthalmol. 2015; 26(5):371-4.
57. Shainberg MJ. Nonsurgical treatment of teenagers with high AC/a ratio esotropia. Am Orthopt J. 2014;64:32-6.

58. Hatt SR, Wang X, Holmes JM: Interventions for dissociated vertical deviation. In: Cochrane Database of Systematic Reviews. John Wiley \& Sons, Ltd; 2015.

59. Christoff A, Raab EL, Guyton DL, Brodsky MC, Fray KJ, Merrill K, Hennessey CC, Bothun ED, Morrison DG. DVD--a conceptual, clinical, and surgical overview. J Aapos: Am Assoc Pedia Ophthalmol Strabismus. 2014;18(4):378-84.

60. Rajavi Z, Molazadeh A, Ramezani A, Yaseri M. A randomized clinical trial comparing myectomy and recession in the management of inferior oblique muscle overaction. J Pedia Ophthalmol Strabismus. 2011;48(6):375-80.

61. MacKenzie K, Hancox J, McBain H, Ezra DG, Adams G, Newman S: Psychosocial interventions for improving quality of life outcomes in adults undergoing strabismus surgery. In: Cochrane Database of Systematic Reviews. John Wiley \& Sons, Ltd; 2016.

62. McBain HB, Au CK, Hancox J, MacKenzie KA, Ezra DG, Adams GGW, Newman SP. The impact of strabismus on quality of life in adults with and without diplopia: a systematic review. Surv Ophthalmol. 2014;59(2):185-91.

63. Minguini N, de Carvalho KMM, Bosso FLS, Hirata FE, Kara-José N. Surgery with intraoperative botulinum toxin-a injection for the treatment of largeangle horizontal strabismus: a pilot study. Clinics. 2012;67(3):279-82.

64. Gunton KB. Impact of strabismus surgery on health-related quality of life in adults. Curr Opin Ophthalmol. 2014;25(5):406-10.

65. Haridas A, Sundaram V. Adjustable versus non-adjustable sutures for strabismus. Cochrane Database Syst Rev. 2018. Issue 3. Art. No.: CD004240. https://doi.org/10.1002/14651858.CD004240.pub4.

66. Saxena R, Kakkar A, Menon V, Sharma P, Phuljhele S. Evaluation of factors influencing distance stereoacuity on Frisby-Davis distance test (FD2) in intermittent exotropia. Br J Ophthalmol. 2011;95(8):1098-101.

67. Yilmaz A, Kose S, Yilmaz SG, Uretmen O. The impact of prism adaptation test on surgical outcomes in patients with primary exotropia. Clin Exp Optometry. 2015;98(3):224-7.

68. Kelkar J, Gopal S, Shah R, Kelkar A. Intermittent exotropia: Surgical treatment strategies. Indian J Ophthalmol. 2015;63(7):566-9.

69. Gross NJ, Link H, Biermann J, Kiechle M, Lagreze WA. Induced Incomitance of one muscle strabismus surgery in comparison to unilateral recess-resect procedures. Klinische Monatsblatter fur Augenheilkunde. 2015;232(10):1174-7.

70. Nabie R, Azadeh M, Andalib D, Mohammadlou FS. Anchored versus conventional hang-back bilateral lateral rectus muscle recession for exotropia. J AAPOS. 2011:15(6):532-5.

71. Wang B, Wang L, Wang Q, Ren M. Comparison of different surgery procedures for convergence insufficiency-type intermittent exotropia in children. Br J Ophthalmol. 2014;98(10):1409-13.

72. Wang X, Gao X, Xiao M, Tang L, Wei X, Zeng J, Li Y. Effectiveness of strabismus surgery on the health-related quality of life assessment of children with intermittent exotropia and their parents: a randomized clinical trial. J Aapos: Am Assoc Pedia Ophthalmol Strabismus. 2015;19(4):298-303.

73. Jones-Jordan L, Wang X, Scherer RW, Mutti DO: Spectacle correction versus no spectacles for prevention of strabismus in hyperopic children. In: Cochrane Database of Systematic Reviews. John Wiley \& Sons, Ltd; 2014.

74. Pediatric Eye Disease Investigator G, Cotter SA, Mohney BG, Chandler DL, Holmes JM, Repka MX, Melia M, Wallace DK, Beck RW, Birch EE, et al. A randomized trial comparing part-time patching with observation for children 3 to 10 years of age with intermittent exotropia. Ophthalmology. 2014:121(12):2299-310.

75. Mohney BG, Cotter SA, Chandler DL, Holmes JM, Chen AM, Melia M, Donahue SP, Wallace DK, Kraker RT, Christian ML, et al. A randomized trial comparing part-time patching with observation for intermittent exotropia in children 12 to 35 months of age. Ophthalmology. 2015;122(8):1718-25.

76. Joyce KE, Beyer F, Thomson RG, Clarke MP. A systematic review of the effectiveness of treatments in altering the natural history of intermittent exotropia. Br J Ophthalmol. 2015;99(4):440-50.

77. Clarke M, Hogan V, Buck D, Shen J, Powell C, Speed C, Tiffin P, Sloper J, Taylor R, Nassar M, et al. An external pilot study to test the feasibility of a randomised controlled trial comparing eye muscle surgery against active monitoring for childhood intermittent exotropia $[X(T)]$. Health Technol Asse (Winchester, England). 2015;19(39):1-144.

78. Buck D, McColl E, Powell CJ, Shen J, Sloper J, Steen N, Taylor R, Tiffin P, Vale $L$, Clarke MP. Surgery versus Active Monitoring in Intermittent Exotropia (SamExo): study protocol for a pilot randomised controlled trial. Trials [Electronic Resource]. 2012;13:192. 
79. Tailor V, Balduzzi S, Hull S, Rahi J, Schmucker C, Virgili G, Dahlmann-Noor A: Tests for detecting strabismus in children age 1 to 6 years in the community. In: Cochrane Database of Systematic Reviews. John Wiley \& Sons, Ltd; 2014.

80. Rowe FJ, Noonan CP, Garcia-Finana M, Dodridge CS, Howard C, Jarvis KA, MacDiarmid SL, Maan T, North L, Rodgers H: Interventions for eye movement disorders due to acquired brain injury. In: Cochrane Database of Systematic Reviews. John Wiley \& Sons, Ltd; 2014

81. Pollock A, Hazelton C, Henderson CA, Angilley J, Dhillon B, Langhorne P, Livingstone K, Munro FA, Orr H, Rowe FJ et al: Interventions for disorders of eye movement in patients with stroke. In: Cochrane Database of Systematic Reviews. John Wiley \& Sons, Ltd; 2011

82. Minakaran N, Ezra Daniel G: Rituximab for thyroid-associated ophthalmopathy. In: Cochrane Database of Systematic Reviews. John Wiley \& Sons, Ltd; 2013.

83. Boboridis KG, Bunce C. Surgical orbital decompression for thyroid eye disease. Cochrane Database Syst Rev. 2011;12:CD007630.

84. Rajendram R, Bunce C, Lee Richard WJ, Morley Ana MS: Orbital radiotherapy for adult thyroid eye disease. In: Cochrane Database of Systematic Reviews. John Wiley \& Sons, Ltd; 2012

85. Hertle RW, Yang D, Adkinson T, Reed M. Topical brinzolamide (Azopt) versus placebo in the treatment of infantile nystagmus syndrome (INS). Br J Ophthalmol. 2015;99(4):471-6.

86. Jayaramachandran P, Proudlock FA, Odedra N, Gottlob I, McLean RJ. A randomized controlled trial comparing soft contact lens and rigid gaspermeable lens wearing in infantile nystagmus. Ophthalmology. 2014; 121(9):1827-36.

87. Claassen J, Spiegel R, Kalla R, Faldon M, Kennard C, Danchaivijitr C, Bardins S, Rettinger N, Schneider E, Brandt T, et al. A randomised double-blind, crossover trial of 4-aminopyridine for downbeat nystagmus--effects on slowphase eye velocity, postural stability, locomotion and symptoms. J Neurol Neurosurg Psychiatry. 2013;84(12):1392-9.

88. Boxer AL, Lang AE, Grossman M, Knopman DS, Miller BL, Schneider LS, Doody RS, Lees A, Golbe LI, Williams DR, et al. Davunetide in patients with progressive supranuclear palsy: a randomised, double-blind, placebocontrolled phase 2/3 trial. Lancet Neurol. 2014;13(7):676-85.

89. Wang SA, Yang J, Zhang GB, Feng YH, Wang F, Zhou PY. Effect of mecobalamin treatment on the recovery of patients with posterior communicating artery aneurysm inducing oculomotor nerve palsy after operation. European Review for Medical \& Pharmacological Sciences. 2015; 19(14):2603-7.

90. Savino G, Mandara E, Gari M, Battendieri R, Corsello SM, Pontecorvi A. Intraorbital injection of rituximab versus high dose of systemic glucocorticoids in the treatment of thyroid-associated orbitopathy. Endocrine. 2015;48(1):241-7.

91. Leo M, Marcocci C, Pinchera A, Nardi M, Megna L, Rocchi R, Latrofa F, Altea MA, Mazzi B, Sisti E, et al. Outcome of Graves' orbitopathy after total thyroid ablation and glucocorticoid treatment: Follow-up of a randomized clinical trial. J Clin Endocrinol Metab. 2012;97(1).

92. Moleti M, Violi MA, Montanini D, Trombetta C, Di Bella B, Sturniolo G, Presti S, Alibrandi A, Campenní A, Baldari S, et al. Radioiodine ablation of postsurgical thyroid remnants after treatment with recombinant human TSH (rhTSH) in patients with moderate-to-severe graves' orbitopathy (GO): a prospective, randomized, single-blind clinical trial. J Clin Endocrinol Metab. 2012;97(1):E44-E48. https://doi.org/10.1210/jc.2011-2077.

93. Bi J-Q, Li W, Yang Q, Li B-I, Meng Q-G, Y-f L. Acupuncture for the treatment of oculomotor paralysis: a pilot randomised controlled trial. Evidence-based Complementary \& Alternative Medicine (eCAM). 2016:1-6.

94. Leclair-Visonneau L, Rouaud T, Debilly B, Durif F, Houeto JL, Kreisler A, Defebvre L, Lamy E, Volteau C, Nguyen JM, et al. Randomized placebocontrolled trial of sodium valproate in progressive supranuclear palsy. Clin Neurol Neurosurg. 2016;146:35-9.

95. Stan MN, Garrity JA, Carranza Leon BG, Prabin T, Bradley EA, Bahn RS. Randomized controlled trial of rituximab in patients with Graves' orbitopathy. J Clin Endocrinol Metab. 2015;100(2):432-41.

96. Suhler EB, Lim LL, Beardsley RM, Giles TR, Pasadhika S, Lee ST, de Saint SA, Butler NJ, Smith JR, Rosenbaum JT. Rituximab therapy for refractory orbital inflammation: results of a phase 1/2, dose-ranging, randomized clinical trial. JAMA Ophthalmology. 2014;132(5):572-8.

97. Marcocci C, Kahaly GJ, Krassas GE, Bartalena L, Prummel M, Stahl M, Altea MA, Nardi M, Pitz S, Boboridis K, et al. Selenium and the course of mild Graves' orbitopathy. N Engl J Med. 2011;364(20):1920-31.
98. Watanabe N, Noh JY, Kozaki A, Iwaku K, Sekiya K, Kosuga Y, Matsumoto M, Suzuki M, Yoshihara A, Ohye H, et al. Radioiodine-associated exacerbation of Graves' Orbitopathy in the Japanese population: randomized prospective study. J Clin Endocrinol Metab. 2015;100(7):2700-8.

99. Shiber S, Stiebel-Kalish H, Shimon I, Grossman A, Robenshtok E. Glucocorticoid regimens for prevention of Graves' ophthalmopathy progression following radioiodine treatment: systematic review and metaanalysis. Thyroid. 2014;24(10):1515-23.

100. Thiagarajan P, Ciuffreda KJ, Capo-Aponte JE, Ludlam DP, Kapoor N. Oculomotor neurorehabilitation for reading in mild traumatic brain injury (mTBI): an integrative approach. Neurorehabilitation. 2014;34(1):129-46.

101. Zhu W, Ye L, Shen L, Jiao Q, Huang F, Han R, Zhang X, Wang S, Wang W, Ning $G$. A prospective, randomized trial of intravenous glucocorticoids therapy with different protocols for patients with graves' ophthalmopathy. J Clin Endocrinol Metab. 2014;99(6):1999-2007.

102. Mancuso M, Orsucci D, Calsolaro V, Logerfo A, Allegrini L, Petrozzi L, Simoncini C, Rocchi A, Trivella F, Murri L, et al. Tetracycline treatment in patients with progressive external ophthalmoplegia. Acta Neurol Scand. 2011;124(6):417-23.

103. Barczyński M, Konturek A, Hubalewska-Dydejczyk A, Gołkowski F, Nowak W. Randomized clinical trial of bilateral subtotal thyroidectomy versus total thyroidectomy for Graves' disease with a 5-year follow-up. Br J Surg. 2012;99(4): 515-22.

104. Täeb D, Bournaud C, Eberle MC, Catargi B, Schvartz C, Éatrice Cavarec MB, Faugeron I, Toubert ME, Benisvy D, Archange C, et al. Quality of life, clinical outcomes and safety of early prophylactic levothyroxine administration in patients with Graves' hyperthyroidism undergoing radioiodine therapy: a randomized controlled study. Eur J Endocrinol. 2016;174(4):491-502.

105. Cheung K, Voineskos SH, Avram R, Sommer DD. A systematic review of the endoscopic management of orbital floor fractures. JAMA Facial Plastic Surgery. 2013;15(2):126-30.

106. Wu YT, Cafiero-Chin M, Marques C. Wall-eyed bilateral internuclear ophthalmoplegia: review of pathogenesis, diagnosis, prognosis and management. Clin Exp Optometry. 2015;98(1):25-30.

107. Wickwar S, McBain HB, Ezra DG, Hirani SP, Rose GE, Newman SP. What are the psychosocial outcomes of treatment for thyroid eye disease? A systematic review. Thyroid. 2014;24(9):1407-18.

108. Mou P, Jiang LH, Zhang Y, Li YZ, Lou H, Zeng CC, Wang QH, Cheng JW, Wei RL. Common Immunosuppressive Monotherapy for Graves' Ophthalmopathy: A Meta-Analysis. PLoS ONE [Electronic Resource]. 2015; 10(10):e0139544.

109. Chundury RV, Weber AC, Perry JD. Orbital radiation therapy in thyroid eye disease. Ophthalmic Plast Reconstr Surg. 2016:32(2):83-9.

110. Jellema HM, Braaksma-Besselink Y, Limpens J, von Arx G, Wiersinga WM, Mourits MP. Proposal of success criteria for strabismus surgery in patients with Graves' orbitopathy based on a systematic literature review. Acta Opthalmologica. 2015;93(7):601-9.

111. Boboridis KG, Uddin J, Mikropoulos DG, Bunce C, Mangouritsas G, Voudouragkaki IC, Konstas AG. Critical appraisal on orbital decompression for thyroid eye disease: a systematic review and literature search. Adv Ther. 2015;32(7):595-611.

112. Shi SM, He YB. Effectiveness of somatostatin analogs versus placebo for graves' ophthalmopathy: a meta-analysis. Chin J Evid Based Med. 2013;13(1): 106-11.

113. Chen DY, Schneider PF, Zhang XS, Luo XY, He ZM, Chen TH. Changes in graves' ophthalmopathy after radioiodine and anti-thyroid drug treatment of Graves' disease from 2 prospective, randomized, open-label, blinded end point studies. Experimental \& Clinical Endocrinology \& Diabetes. 2014;122(1):1-6.

114. Gao G, Dai J, Qian Y, Ma F. Meta-analysis of methylprednisolone pulse therapy for Graves' ophthalmopathy. Clin Exp Ophthalmol. 2014;42(8):769-77.

115. Bartalena L, Krassas GE, Wiersinga W, Marcocci C, Salvi M, Daumerie C, Bournaud C, Stahl M, Sassi L, Veronesi G, et al. Efficacy and safety of three different cumulative doses of intravenous methylprednisolone for moderate to severe and active Graves' orbitopathy. J Clin Endocrinol Metab. 2012;97(12): 4454-63.

116. Salvi M, Vannucchi G, Curro N, Campi I, Covelli D, Dazzi D, Simonetta S, Guastella C, Pignataro L, Avignone S, et al. Efficacy of B-cell targeted therapy with rituximab in patients with active moderate to severe Graves' orbitopathy: a randomized controlled study. J Clin Endocrinol Metab. 2015; 100(2):422-31.

117. Pediatric Eye Disease Investigator G, Scheiman MM, Hoover DL, Lazar EL, Cotter SA, Kraker RT, Kulp MT, Wallace DK, Jenewein EC, Gallaway MF, et al. 
Home-Based Therapy for Symptomatic Convergence Insufficiency in Children: A Randomized Clinical Trial. Optometry and Vision Science. 2016; 93:1457-65.

118. Scheiman M, Cotter S, Kulp MT, Mitchell GL, Cooper J, Gallaway M, Hopkins KB, Bartuccio M, Chung I. Treatment of accommodative dysfunction in children: results from a randomized clinical trial. Optom Vis Sci. 2011;88(11):1343-52.

119. Joshi S, Kassira W, Thaller SR. Overview of pediatric orbital fractures. J Craniofacial Surgery. 2011;22(4):1330-2.

120. Ehrt O. Infantile and acquired nystagmus in childhood. Eur J Paediatr Neurol. 2012;16(6):567-72.

121. Akar S, Gökyiğit B, Yilmaz OF. Graded anterior transposition of the inferior oblique muscle for V-pattern strabismus. J AAPOS. 2012;16(3):286-90.

122. Stotland MA, Do NK. Pediatric orbital fractures. J Craniofacial Surgery. 2011; 22(4):1230-5.

123. Barnhardt C, Cotter SA, Mitchell GL, Scheiman M, Kulp MT. Symptoms in children with convergence insufficiency: before and after treatment. Optom Vis Sci. 2012;89(10):1512-20.

124. Horan LA, Ticho BH, Khammar AJ, Allen MS, Shah BA. Is the convergence insufficiency symptom survey specific for convergence insufficiency? A prospective, randomized study. Am Orthopt J. 2015;65:99-103.

125. Scheiman M, Gwiazda J, Li T: Non-surgical interventions for convergence insufficiency. In: Cochrane Database of Systematic Reviews. John Wiley \& Sons, Ltd; 2011.

126. Theodorou M, Karim R: Non-surgical interventions for nystagmus developing in the first year of life (infantile nystagmus). In: Cochrane Database of Systematic Reviews. John Wiley \& Sons, Ltd; 2014.

127. Benatar M, Kaminski H: Medical and surgical treatment for ocular myasthenia. In: Cochrane Database of Systematic Reviews. John Wiley \& Sons, Ltd; 2012.

128. Cooper J, Jamal N. Convergence insufficiency-a major review. Optometry (St Louis, Mo). 2012;83(4):137-58

129. Manley DR, Alvi RA. Brown's syndrome. Curr Opin Ophthalmol. 2011;22(5): $432-40$

130. Curi RLN, Costa I, Barroso TGM. VI nerve palsy (abducens palsy). Revista Brasileira De Oftalmologia. 2013;72(1):59-69.

131. Engel JM. Treatment and diagnosis of congenital fourth nerve palsies: an update. Curr Opin Ophthalmol. 2015;26(5):353-6.

132. Strupp M, Kremmyda O, Adamczyk C, Böttcher N, Muth C, Yip CW, Bremova T. Central ocular motor disorders, including gaze palsy and nystagmus. J Neurol. 2014;261 (SUPPL. 2):542-58.

133. Nair AG, Patil-Chhablani P, Venkatramani DV, Gandhi RA. Ocular myasthenia gravis: a review. Indian J Ophthalmol. 2014;62(10):985-91.

134. Singh A, Bahuguna C, Nagpal R, Kumar B. Surgical management of third nerve palsy. Oman J Ophthalmol. 2016;9(2):80-6.

135. Fraser CL, Skalicky SE, Gurbaxani A, McCluskey P. Ocular myositis. Current Allergy Asthma Reports. 2013;13(3):315-21.

136. Ghasia FF, Shaikh AG. Pattern strabismus: where does the brain's role end and the muscle's begin? J Ophthalmol. 2013;2013.

137. Ehrhardt D, Eggenberger E. Medical treatment of acquired nystagmus. Curr Opin Ophthalmol. 2012;23(6):510-6.

138. Ranka MP, Liu GT, Nam JN, Lustig MJ, Schwartz SR, Hall LS, Furlan LE, Ceisler EJ, Steele MA. Bilateral posterior tenectomy of the superior oblique muscle for the treatment of A-pattern strabismus. Journal of AAPOS. 2014;18(5):437-40.

139. Li Y, Ma H, Zhao K. Effects of bilateral superior oblique "hang-Back" recession in treatment of a-pattern strabismus with superior oblique overaction. Strabismus. 2016;24(1):1-6.

140. Awadein A. Lateral rectus recession with/without transposition in V-pattern exotropia without inferior oblique overaction. Can J Ophthalmol. 2013:48(6):500-5.

141. Dubois L, Steenen SA, Gooris PJJ, Mourits MP, Becking AG. Controversies in orbital reconstruction - II. Timing of post-traumatic orbital reconstruction: a systematic review. Int J Oral Maxillofac Surg. 2015;44(4):433-40.

142. Benatar M, McDermott MP, Sanders DB, Wolfe Gl, Barohn RJ, Nowak RJ, Hehir M, Juel V, Katzberg H, Tawil R. Efficacy of prednisone for the treatment of ocular myasthenia (EPITOME): a randomized, controlled trial. Muscle Nerve. 2016;53(3):363-9.

143. Benatar M, Sanders DB, Wolfe Gl, McDermott MP, Tawil R. Design of the efficacy of prednisone in the treatment of ocular myasthenia (EPITOME) trial. Ann N Y Acad Sci. 2012;1275:17-22.

144. Ji XJ, Zhou LY, Si CQ, Guo Q, Feng GZ, Gang BZ. Efficacy observation on electroacupuncture in the treatment of oculomotor impairment caused by ophthalmic nerve injury. Zhongguo Zhenjiu. 2013;33(11):975-9.
145. Greven MA, Nelson LB. Four-muscle tenotomy surgery for nystagmus. Curr Opin Ophthalmol. 2014;25(5):400-5.

146. Wan KH, Chong KKL, Young AL. The role of computer-assisted Technology in Post-Traumatic Orbital Reconstruction: a PRISMA-driven systematic review. Sci Rep. 2015;5.

147. Cacho-Martínez P, García-Muñoz Á, Ruiz-Cantero MT. Is there any evidence for the validity of diagnostic criteria used for accommodative and nonstrabismic binocular dysfunctions? J Opt. 2014;7(1):2-21.

148. Saldanha IJ, Dickersin K, Wang X, Li T. Outcomes in Cochrane Systematic Reviews Addressing Four Common Eye Conditions: An Evaluation of Completeness and Comparability. PLoS One. 2014;9(10). https://doi.org/10. 1371/journal.pone.0109400.

149. Krezel AK, Hogg RE, Azuara-Blanco A. Patient-reported outcomes in randomised controlled trials on age-related macular degeneration. $\mathrm{Br} J$ Ophthalmol. 2015;99(11):1560-4.

150. Ismail R, Ramsay CR, Azuara-Blanco A. Outcome measures in Glaucoma: a systematic review of Cochrane reviews and protocols. J Glaucoma. 2015; 24(7):533-8.

151. Denniston AK, Holland GN, Kidess A, Nussenblatt RB, Okada AA, Rosenbaum $J$, Dick AD. Heterogeneity of primary outcome measures used in clinical trials of treatments for intermediate, posterior, and panuveitis. Orphanet J Rare Dis. 2015;10(1):1-11.

\section{Ready to submit your research? Choose BMC and benefit from:}

- fast, convenient online submission

- thorough peer review by experienced researchers in your field

- rapid publication on acceptance

- support for research data, including large and complex data types

- gold Open Access which fosters wider collaboration and increased citations

- maximum visibility for your research: over $100 \mathrm{M}$ website views per year

At $\mathrm{BMC}$, research is always in progress.

Learn more biomedcentral.com/submissions 